\title{
Physical performance and self-report outcomes associated with use of passive, adaptive, and active prosthetic knees in persons with unilateral, transfemoral amputation: Randomized crossover trial
}

\author{
Brian J. Hafner, PhD; ${ }^{*}$ Robert L. Askew, PhD, MPH ${ }^{2}$ \\ Departments of ${ }^{1}$ Rehabilitation Medicine and ${ }^{2}$ Psychology, University of Washington, Seattle, WA
}

\begin{abstract}
Prosthetic knees are a vital component in an artificial limb. Contemporary knees include passive (mechanical), adaptive (computerized), or active (motorized) control systems and have the potential to mitigate amputation-related functional impairments and activity limitations. A 14 mo randomized crossover trial was conducted. Participants $(n=12$, mean age $=58 \mathrm{yr})$ were tested under three conditions: passive control (existing knee), adaptive control (Ossur Rheo Knee II), and active control (Ossur Power Knee II). Training and acclimation time were provided to participants in the adaptive and active knees. Outcome measures included indoor tests (Timed Up and Go test [TUG], stairs, and ramp), outdoor tests (walking course and perceived exertion), step activity monitor, self-report surveys (mobility, balance confidence, physical function, fatigue, and general health), and fall incidence. Mixed-effects linear regression modeling was used to evaluate data. Compared with passive control, adaptive control significantly improved comfortable TUG time (difference $=0.91 \mathrm{~s}, p=0.001$ ) and reported physical function (difference $=1.26$ [T-score], $p=0.03$ ). Active control significantly increased comfortable TUG, fast TUG, and ramp times (difference $=3.02,2.66$, and $0.96 \mathrm{~s}$, respectively, all $p<0.03$ ) and increased balance confidence (difference $=3.77, p=0.003$ ) compared with passive control. Findings suggest that adaptive knee control may enhance function compared with passive control but that active control can restrict mobility in middle-age or older users with transfemoral amputation.
\end{abstract}

Clinical Trial Registration: ClinicalTrials.gov; "Use of Passive, Adaptive, and Active Prosthetic Knees in Persons With Unilateral, Transfemoral Amputation": NCT02219230;

https://clinicaltrials.gov/ct2/show/NCT02219230
Key words: adaptive control system, amputation, amputee, artificial limb, longitudinal studies, measurement, outcomes evaluation, physical performance testing, prosthetic knee, questionnaires.

\begin{abstract}
Abbreviations: $\mathrm{ABC}=$ Activities-Specific Balance Confidence scale, $\mathrm{HRQOL}=$ health-related quality of life, $\mathrm{MFCL}=$ Medicare Functional Classification Level, MR = magnetorheologic, OC = obstacle course, PEQ-MS = Prosthesis Evaluation Questionnaire-Mobility Subscale, PROMIS = PatientReported Outcomes Measurement Information System, PROMIS-FAT $=$ PROMIS-Fatigue, PROMIS-G-MH $=$ PROMIS-Global Mental Health, PROMIS-G-PH = PROMISGlobal Physical Health, PROMIS-GH = PROMIS-Global Health, PROMIS-PF $=$ PROMIS-Physical Function, RPE $=$ Borg Rating of Perceived Exertion, SCS $=$ Socket Comfort Score, $\mathrm{SD}=$ standard deviation, TFA $=$ transfemoral amputation, TRT $=$ Timed Ramp Test, TST $=$ Timed Stair Test, TUG $=$ Timed Up and Go test, TUG-Comf = TUG comfortable speed, TUG-Fast $=$ TUG fast speed, VAS $=$ visual analog scale, VAS$\mathrm{M}=$ VAS mental exertion, VAS-P = VAS physical exertion.

*Address all correspondence to Brian J. Hafner, PhD; Department of Rehabilitation Medicine, University of Washington, 1959 NE Pacific St, Box 356490, Seattle, WA 98195; 206-685-4048; fax: 206-685-3244.
\end{abstract}

Email: bhafner@uw.edu

http://dx.doi.org/10.1682/JRRD.2014.09.0210 


\section{INTRODUCTION}

Transfemoral amputation (TFA) involves significant loss of functional anatomy, including lower-limb structures (bones, joints, and muscles) vital to performing bipedal activities and participating in a wide range of life activities. Although individuals with TFA often receive a prosthesis (i.e., artificial limb) to replace amputated or absent anatomical structures, notable functional deficits remain. Specifically, TFA has been associated with decreased balance [1-5]; increased metabolic energy expenditure while walking [6-9]; decreased walking speed $[7,10-11]$; increased frequency of stumbles and falls [12-13]; reduced activity level [14-16]; and difficulties negotiating uneven terrain, hills, and stairs [1720]. These physical impairments and functional limitations likely contribute to the reduced health-related quality of life (HRQOL) [21-24] reported by people with TFA compared with nonamputee (nondisabled) norms [25-26]. Interventions capable of addressing the challenges inherent to proximal lower-limb amputations are therefore much desired and are considered vital to the rehabilitation of individuals with TFA.

A key element in the design and function of a TFA prosthesis is the prosthetic knee. Functional behavior of the knee is primarily determined by its control system, which may be described as passive, adaptive, or active [27]. Passive control systems regulate knee movement using mechanical friction or fluidic flow control. Many prosthetic knees incorporate a mechanical-fluidic control system that allows or restricts flow through a hydraulic or pneumatic cylinder [28-29]. Adaptive control systems use a computer and data from intrinsic sensors to constantly and rapidly change the knee's resistance to flexion and extension [27]. Most contemporary microprocessorcontrolled prosthetic knees include systems that adaptively control the flow of pneumatic and/or hydraulic fluids or change the viscosity of magnetorheologic (MR) fluids working in shear mode [30]. Active control systems use an electromechanical motor to regulate motion and position of the knee joint [27]. Only one commercially available knee unit currently uses an active control system [31-33], although others are in development [34-36] and may soon be available to end users.

Adaptive and active prosthetic knee-control systems offer the potential to mitigate many of the functional challenges associated with use of a passive TFA prosthesis. Active prosthetic knee systems may be of particular advantage to older individuals or to those with lower functional capabilities because such individuals may lack the strength and/or muscular control necessary to effectively use a passive prosthetic knee. Adaptive microprocessor-controlled prosthetic knees have been well studied, and their use has been associated with a variety of functional benefits when compared with use of passive mechanical-control prosthetic knees [37], including improved balance [38]; increased walking speeds [3942]; decreased daily metabolic energy expenditure [43]; improved ability to negotiate stairs [42,44-45], hills [4445], and uneven terrain [42,44-46]; and reduced frequency of falls $[42,44-45]$. Active knee systems have received comparably less attention in the scientific literature, but are purported to improve users' ability to rise from a chair (i.e., sit-to-stand) [33,47], ascend steps and slopes [31-33], walk long distances [33], and walk over uneven terrain [32], as well as limit the frequency of falling [32]. Further, use of an active prosthesis is believed to enhance function among individuals who may be limited in their safe and effective use of a passive prosthesis [32].

Although much is known about the performance of prosthetic knee systems, additional research is needed. A key limitation to the existing adaptive knee literature is that the majority of findings to date have been based on a single model (i.e., Ottobock C-Leg) (Ottobock; Duderstadt, Germany) that uses a specific microprocessorcontrolled hydraulic control system [37]. Other adaptive or active knee technologies, such as the MR system present in the Össur Rheo Knee II (Össur hf; Reykjavík, Iceland), or the harmonic drive system present in the Össur Power Knee have not been well studied, with a few notable exceptions [39,47-51]. These prior studies have primarily focused on evaluation of laboratory-based biomechanical outcomes (e.g., kinetics and kinematics) and have not directly evaluated users' functional outcomes over longer periods.

The purpose of this study, therefore, was to assess and compare physical performance and self-reported outcomes that may be attributed to use of prosthetic knees with passive, adaptive, and active control in persons with unilateral TFA. Specifically, we were interested in evaluating the effects of different knee technologies on middle-age or older individuals. We hypothesized that use of knees with active and adaptive control would significantly improve functional outcomes (i.e., walking performance on level terrain, stairs, inclines, and uneven terrain and step activity) and self-reported outcomes (i.e., mobility, balance, 
physical performance, fatigue, exertion, concentration, health, and quality of life) compared with use of knees with passive control systems. Further, we hypothesized that performance of functional activities that include tasks that are generally achieved through active knee extension (e.g., sit-to-stand, ramp ascent, stair ascent, and distance walking) would be significantly improved when users wear a prosthesis with an active knee-control system compared with an adaptive knee-control system.

\section{METHODS}

\section{Study Participants}

Healthy, experienced prosthetic limb users were recruited to participate in the study. Selection criteria were applied to elicit participation from a relatively homogenous population. Inclusion criteria for participants were age 45 to $75 \mathrm{yr}$ (i.e., middle age or older, as classified by the U.S. Census Bureau [52]), weight $<275 \mathrm{lb}$ $(125 \mathrm{~kg})$, unilateral TFA, nonvascular amputation etiology, amputation at least 2 yr prior to the study, and classification by the study prosthetist as an unlimited community ambulator (i.e., Medicare Functional Classification Level [MFCL] or K-level of 3) [53]. Participants were also required to have a healthy residual limb with stable limb volume, as evidenced by use of an unmodified prosthetic socket for at least 6 mo prior to the start of the study. Lastly, participants were required to own, and use daily, an endoskeletal prosthesis with a comfortable socket and a passive, non-microprocessor-controlled prosthetic knee. Exclusion criteria included other major limb amputations (i.e., arms or contralateral leg), open wounds or sores on the residual limb, complete reliance on an assistive device for ambulation (i.e., the individual required a cane or walker to safely ambulate indoors), or an expected change to the prosthetic prescription (e.g., socket replacement) within the next 15 mo.

Candidate participants were recruited using informational flyers posted at prosthetic clinics and hospitals in the greater Puget Sound area (i.e., Seattle, Washington, and surrounding areas). Interested individuals were first screened by telephone for basic selection criteria (e.g., age, amputation level, etiology). Eligible candidates were then evaluated in person by the study prosthetist to confirm eligibility and verify their ability to perform the test measures.

\section{Study Design}

A longitudinal, randomized crossover trial was conducted to test the developed hypotheses (Figure 1). Study participants were studied over a period of 14 mo under three different prosthetic knee conditions (i.e., passive, adaptive, and active control). The study included four phases termed Baseline 1, Intervention 1, Baseline 2, and Intervention 2. When in the baseline phases of the study (i.e., Baseline 1 or 2), participants wore a prosthesis (i.e., an artificial limb that includes a socket, knee, pylon, foot, and necessary connectors) with their existing passive control prosthetic knee. Details of the test prostheses are provided subsequently (see "Knee Conditions" and "Procedures"). When in the intervention phases (i.e., Intervention 1 or 2), participants wore a prosthesis with an adaptive or active control knee. Participants were

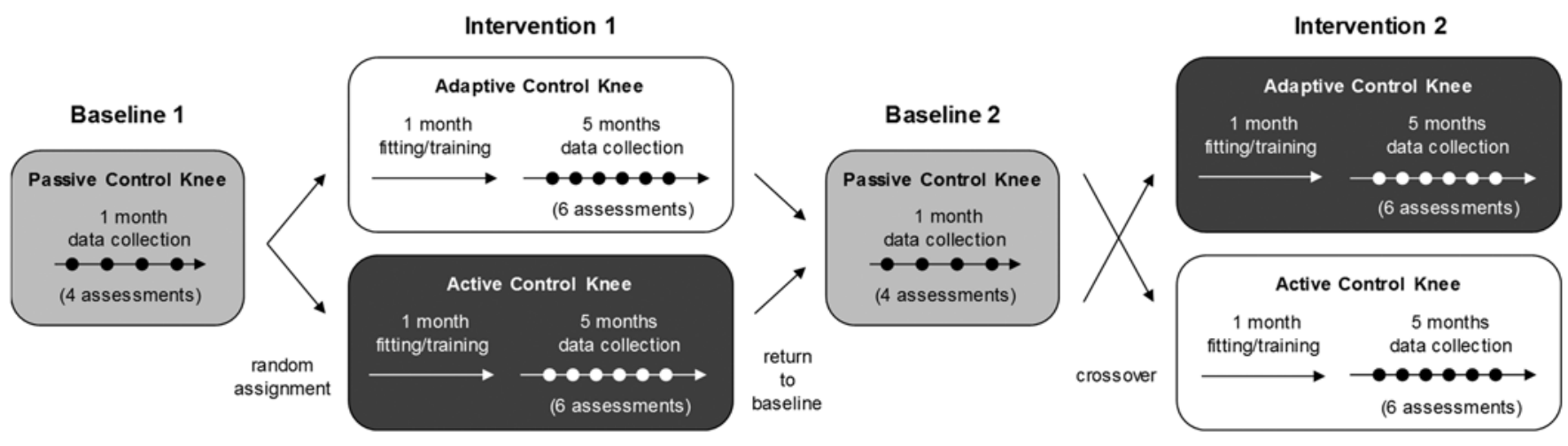

Figure 1.

Graphical representation of study design and participant assessment schedule. 
randomly assigned to one of two wear protocols (i.e., passive-adaptive-passive-active or passive-active-passiveadaptive). The length of the baseline and intervention phases differed. Given participants' prior experience with passive knee control, baseline phases were only 1 mo in duration. Intervention phases were scheduled to be $6 \mathrm{mo}$ in duration (i.e., $1 \mathrm{mo}$ of training and 5 mo of assessment) to allow participants time to acclimate to the adaptive and active control systems.

\section{Knee Conditions}

Participants were tested under three distinct prosthetic knee conditions (i.e., passive, adaptive, and active knee control). The exact model of knee used in the passive knee condition was determined by the knee that each participant had in his prosthesis when the study began. Passive control knees therefore varied among participants, but were represented by knees with hydraulic or pneumatic control systems, as these knees are typically prescribed for individuals classified as MFCL 3. The prosthetic knees used in the adaptive and active knee conditions were standardized. Participants were all provided with an Össur Rheo Knee II knee when they were in the adaptive knee condition. The Rheo Knee II uses data from intrinsic position, force, and torque sensors (sampled at 1,000 Hz) to control an MR brake [30,48]. The Rheo Knee II control system rapidly and automatically adjusts the MR brake to change the knee's resistance to flexion and extension in response to sensed information. The Rheo Knee II weighs $3.4 \mathrm{lb}(1.5 \mathrm{~kg})$ and includes an integrated battery that typically lasts between 24 and 48 h. Participants were similarly provided with an Össur Power Knee II when they were in the active knee condition. The Power Knee II uses torque and acceleration sensors to control a harmonic drive motor [32]. The motor provides resistance to flexion as well as powered extension of the knee joint. The Power Knee II weighs $7.1 \mathrm{lb}(3.2 \mathrm{~kg})$ and includes a removable battery that typically lasts between 5 and $7 \mathrm{~h}$ under normal use. All participants were provided with two Power Knee II batteries when in the active knee condition. The manufacturer's name and logo were removed from the knees, batteries, chargers, and printed materials to blind participants to the knee condition to the extent possible over an extended period of use (Figure 2). No information about the knees' commercial names or manufacturer was provided to study participants.

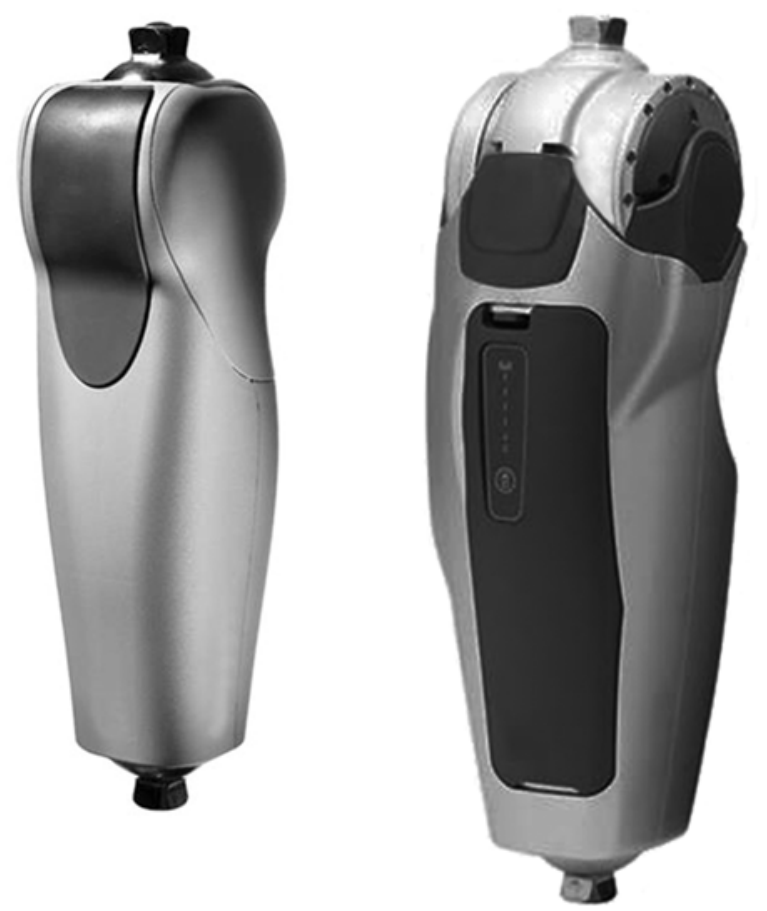

Figure 2.

Active and adaptive knees were blinded to extent possible by removing manufacturer's name and logo from knees and any accessories or informational materials provided to study participants.

\section{Procedures}

Enrolled participants were interviewed by the study prosthetist to obtain demographic and health information including sex, weight, date of birth, date of amputation, amputation etiology, MFCL, and Socket Comfort Score (SCS) [54]. The prosthetist also performed a physical evaluation to document the participant's residual limb length and current prosthetic knee. Participants were each fitted with a new prosthetic pylon and foot (Össur VariFlex) to mitigate influences of dissimilar componentry across the study sample. Participants were instructed to wear their prosthesis with the Vari-Flex foot for $1 \mathrm{wk}$ prior to data collection to allow for acclimation to the new foot. As evidence to guide appropriate time for accommodation to a new prosthetic foot is limited [55], a recommendation by the study prosthetist was used to select the length of the accommodation period. Participants' original sockets were used across all conditions. Fit and alignment was optimized, as needed, by the study prosthetist after the Vari-Flex was integrated into the 
prosthesis or when participants changed knee conditions. Adjustments to fit or alignment were only needed during the training periods. No adjustments were required or made during the periods of data collection presented in this article. Fitting the intervention knees also included new endoskeletal componentry (e.g., offset adaptors), as needed, to ensure proper fit and function of the prosthetic knees. An activity monitor (StepWatch 3) (Orthocare Innovations; Mountlake Terrace, Washington) was also attached to each participant's prosthetic ankle, according to the manufacturer's instructions. Participants were required to demonstrate the ability to walk across a variety of terrain types (e.g., level hall, level carpet, stairs, and ramp) and report the ability to safely use the prosthesis prior to leaving the laboratory.

Participants returned to the laboratory to be evaluated regularly throughout the study. Outcomes were assessed weekly when participants were in baseline phases (Baseline 1 and 2) and monthly when they were in the intervention phases (Intervention 1 and 2). Biweekly training sessions and weekly evaluations were also conducted during the first month of both intervention phases to facilitate participants' use of adaptive and active knee-control systems. All participants were provided training to use the knees. A standardized fitting and training protocol was developed in collaboration with the knees' manufacturer (Össur) and included approximately 16 total h (i.e., $4 \mathrm{~h} / \mathrm{wk}$ for $4 \mathrm{wk}$ ) of instruction and practice accomplishing routine tasks (e.g., sit-to-stand, stand-to-sit, stair ascent, stair descent, ramp ascent, ramp descent, and walking over uneven terrain). Training was not explicitly provided to users in the passive knee, as training is typically provided by prosthetic users' normal prosthetist and/or physical therapist. Training provided in this study was specific to the adaptive and active knees and meant to familiarize users with the features of the knee.

Participants were allowed to keep an intervention knee at the end of the study. Participants were allowed to keep the knee if they had learned to use it (i.e., if they had completed a portion of the study while wearing the knee in their prosthesis) and experienced similar or better outcomes compared with their existing knee. Participants were not allowed to keep the knees if they experienced worse outcomes. To mitigate bias of the study results, participants were not informed that they would be allowed to keep either knee prior to completion of the study.

\section{Study Measures}

A suite of outcome measures was developed to assess participants' physical performance, activity, and selfreported physical function, fatigue, HRQOL, mobility, balance, and satisfaction. Both common, standardized instruments and ad hoc instruments were included in the measurement suite. Outcome measures were administered in a standardized order by a single investigator. Upon arrival at the laboratory, participants were seated and the step activity monitor was removed. Participants were administered self-report measures while step activity data were downloaded. Upon completion of the surveys, participants were administered the in-laboratory performance measures, and data were collected on paper forms. Participants were allowed to rest, as needed, between physical performance tests. Lastly, participants were asked to complete an outdoor walking test. Overall, each assessment lasted 1-2 $\mathrm{h}$, depending on the participants' survey time, walking speed, and length of rest periods. Details of the administered measures are provided here.

\section{Physical Performance Measures}

Objective measures of physical performance were selected and developed to evaluate participants' ability to negotiate typical environmental barriers, such as stairs, ramps, and uneven terrain. Physical performance measures were administered by the study prosthetist. Participants were provided standardized verbal instructions that included "When I say go, I would like you to [specific details of the test], please walk at a normal comfortable pace." For all performance measures, time to completion was measured to the nearest one hundredth of a second using a SportCount Chrono 100 stopwatch (Bethesda, Maryland). Participants were allowed to use an assistive device (e.g., cane) during all performance tests as needed. Participants were guarded by a study investigator at all times. However, participants completed all assessments without assistance from investigators.

Timed Up and Go Test. The Timed Up and Go test (TUG) is a basic skills test designed to assess aspects of balance, gait, and physical function [56]. Although the TUG was originally developed for elderly patients, it has shown good reliability and acceptable validity when used with persons with lower-limb loss and has been recommended for use in routine clinical practice and research [56-58]. The TUG has been previously administered both at comfortable and fast walking speeds [59]. This 
test measures participants' ability to rise from a chair, walk $3 \mathrm{~m}$, turn around, return to the chair, and return to a seated position. In this study, participants were asked to perform the TUG twice. Participants were first asked to complete the test at a comfortable speed (TUG-Comf). Next, they were asked to complete the test as quickly and safely as possible (TUG-Fast).

Timed Stair Test. The Timed Stair Test (TST) is a custom test developed to assess participants' ability to ascend and descend stairs. A 36 in.-wide, 6-step staircase (Amramp; South Boston, Massachusetts) with closed risers ( 7 in. high), slip-resistant treads (12 in. deep), and bilateral handrails was constructed for this assessment. The staircase was designed to conform to Americans with Disability Act Standards for Accessible Design [60]. Each participant started the stair assessment standing on a line $2 \mathrm{~m}$ in front of the base of the staircase. Participants were asked to walk forward, ascend the stairs, turn around at the top of the stairs (a $48 \times 96$ in. platform), descend the stairs, and return to the starting position. The stopwatch was started and stopped as the participant crossed a line of tape located $1 \mathrm{~m}$ in front of the stairs. Timing from this location was chosen to mitigate the effects of acceleration and deceleration. Similar timed stair tests have been used by other investigators to study performance, although numbers of steps, size of steps, and location of handrails varied across studies [61-63].

Timed Ramp Test. The Timed Ramp Test (TRT) is a custom test developed to assess participants' ability to ascend and descend a ramp. A 36 in.-wide, $14 \mathrm{ft}$-long ramp (Amramp) with a $15^{\circ}$ grade and bilateral handrails was constructed for this assessment. A $15^{\circ}$ grade was selected to create a challenging physical test that is similar to situations participants may encounter outside of the laboratory (e.g., steep ramps). As with the TST, participants started the assessment standing $2 \mathrm{~m}$ in front of the ramp. They were asked to walk forward, ascend the ramp, turn around on the platform, descend the ramp, and return to the starting position. The stopwatch was similarly started and stopped as participants passed over a tape line $1 \mathrm{~m}$ in front of the ramp.

Obstacle Course. A standardized outdoor obstacle course (OC) was created by the investigators to measure participants' ability to ambulate outdoors. The OC was intended to challenge participants in activities and situations that were likely to be encountered in the community (e.g., a park). The OC was about $0.5 \mathrm{mi}(880 \mathrm{~m})$ in length and included a variety of terrain conditions, including concrete, asphalt, dirt, grass, bark chips, and packed dirt. The OC in this study was longer than indoor [64] or outdoor $[42,44]$ OCs used previously to study outcomes among prosthetic knee users. However, 84 percent of lower-limb prosthesis users report regularly walking outdoor distances of $0.6-1.2 \mathrm{mi}(1-2 \mathrm{~km})$ [65]. Further, it is estimated that people with TFA aged 45 to $75 \mathrm{yr}$ are 60 to 90 percent likely to be capable of walking distances of $500 \mathrm{~m}$ or more [66]. Thus, the developed OC was deemed challenging, but suitable for the purposes of this study. The course included level ground, uneven terrain, slopes (up to a $19^{\circ}$ grade), and stairs. The OC required participants to walk in a straight path, turn both directions, and ascend and descend slopes and stairs. Marker flags were placed along the course to ensure participants walked the same path each time. Participants were asked to walk the course at a comfortable pace. To mitigate the effects of fatigue from prior tests, all participants were brought to the course starting point in a wheelchair and allowed to rest as long as needed. Upon completion of the OC, participants were immediately asked to selfreport, using a visual analog scale (VAS), their level of physical exertion (VAS-P, range 0-100) and the Borg Rating of Perceived Exertion (RPE) centimax (CR100) scale (range 0-120) [67]. Participants were also asked to rate their level of concentration or mental exertion walking the OC using a VAS (VAS-M, range 0-100). VASs are commonly used to measure subjective aspects of health (e.g., pain, fatigue) in health surveys [68]. Here, questions were posed to participants as, "Please rate the level of exertion/concentration you required to complete the obstacle course." Scales were anchored by the descriptors "no exertion/concentration required" and "maximal exertion/concentration required."

Activity Monitor. The StepWatch 3 activity monitor was selected to measure participants' activity over the duration of the study. The StepWatch 3 records the number of steps taken by the wearer in $1 \mathrm{~min}$ increments for periods of up to $60 \mathrm{~d}$. The StepWatch 3 has excellent evidence of measurement reliability and validity across patient populations, including persons with limb loss [69-70]. Data from the activity monitor was downloaded to a laptop computer at each assessment, according the manufacturer's instructions. Step activity data were processed using the StepWatch 3.1 software. Mean daily steps over nontest days were used in this analysis. Test days were removed from the analysis to mitigate the 
influence of travel to the laboratory and performance testing on participants' activity.

\section{Self-Report Measures}

Several standardized self-report outcome measures were included in the measurement suite to assess the participants' perspectives on their physical function, fatigue, HRQOL, mobility, and balance. Self-report measures were administered by paper survey or iPad tablet computer (Apple; Cupertino, California), according to the participant's preference. Computer-administered surveys were created using WebQ open-source survey software hosted at the University of Washington. A total of 62 questions were administered in the survey. Surveys generally required about $10 \mathrm{~min}$ to complete.

Patient-Reported Outcomes Measurement Information System. The Patient-Reported Outcomes Measurement Information System (PROMIS) is a collection of self-report measures that span a variety of health domains [71]. PROMIS instruments were rigorously developed using modern measurement theory to overcome psychometric limitations inherent to many selfreport surveys (e.g., floor effects, ceiling effects, poor sensitivity to change) [72]. PROMIS measures were extensively tested with nondisabled individuals and multiple disease populations [73], including people with limb loss [74]. PROMIS instruments produce a $T$-score that is centered on the U.S. general population mean of 50 with a standard deviation (SD) of 10. The PROMIS-Physical Function (PROMIS-PF), Fatigue (PROMIS-FAT), and Global Health (PROMIS-GH) surveys were administered in this study.

PROMIS-Physical Function. The PROMIS-PF item bank includes 124 items that assess respondents' capacity to perform physical tasks or activities using a 5-point ordinal scale [71,75-76]. Because PROMIS items are individually calibrated, custom short forms can be developed and the resulting $T$-scores remain directly comparable to $T$ scores obtained from the entire bank [77]. Custom short forms may also be more sensitive to measuring a targeted sample than generic short forms. A custom 15-item physical function short form (Appendix, available online only) and scoring table were therefore developed for this study under guidance from a PROMIS investigator. Items selected emphasized situations in which a prosthetic knee would likely affect function.
PROMIS-Fatigue. The PROMIS-FAT item bank includes 95 items that assess respondents' symptoms of fatigue and their resultant effects on respondents' ability to carry out daily activities $[71,76]$. Fatigue items use 5level response categories and prompt respondents to reflect back over the prior $7 \mathrm{~d}$ period. The PROMIS-FAT 7-item short form was administered in this study.

PROMIS-Global Health. The PROMIS-GH short form contains 10 items that assess respondents' overall health [78]. Items include questions from five PROMIS domains (i.e., physical function, fatigue, pain, emotional distress, and social health) as well as items that span some or all of these domains. The PROMIS-GH produces two summary scores - one for physical health (PROMISG-PH) and one for mental health (PROMIS-G-MH). PROMIS-GH measures were included in this study to assess the effects of knee control on overall health and quality of life. We also used the PROMIS-GH for monitoring purposes to identify whether participants experienced global changes in their health that may have positively or negatively affected outcomes measured in this study.

Prosthesis Evaluation Questionnaire-Mobility Scale. The Prosthesis Evaluation Questionnaire-Mobility Scale (PEQ-MS) is a self-report measure of prosthetic mobility for persons with lower-limb loss [79]. The PEQMS was first developed as a 13-item measure with items from both the Ambulation and Transfer subscales of the Prosthesis Evaluation Questionnaire [80]. The PEQ-MS was subsequently revised to a 12-item scale with 5-level ordinal response options using Rasch analysis. Items are individually scored from 0 to 4 and summed to create a PEQ-MS score that ranges from 0 to 48 . The developers showed that the PEQ-MS has evidence of reliability and validity when used with persons with lower-limb amputation [81].

Activities-Specific Balance Confidence Scale. The Activities-Specific Balance Confidence scale (ABC) is a measure of perceived balance that was developed to assess balance in the elderly [82]. The ABC includes 16 items, each scored from 0 to 100 percent. An average percentile score is reported. The $\mathrm{ABC}$ has been used in both 101-level [4,83-85] and 5-level [86] forms to study balance confidence in persons with lower-limb loss. The $\mathrm{ABC}$ shows good evidence of reliability and validity among persons with lower-limb loss [85-86]. 
Falls. Participants were asked at each visit to selfreport the number of falls they had experienced over the previous $7 \mathrm{~d}$. Falls were defined for participants as "an unexpected event in which you lost your balance and landed on the ground, floor, or another lower level" [87]. If one or more fall events had occurred, participants were asked to elaborate on the situation or describe the fall context.

\section{Data Preparation}

Data collected on standardized paper forms (i.e., physical performance measures) were independently entered into an MS Access database (Microsoft; Redmond, Washington) by two different investigators. Double-entry has been shown to reduce data-entry errors by an order of magnitude [88]. Data were verified and reconciled, if needed, prior to analysis. Data obtained electronically (e.g., self-report and step activity data) were imported directly into the database. Summary scores, where indicated, were derived in accordance with outcome measure developers' instructions [76,81,86,89-90]. All summary score calculations were independently verified by two investigators to ensure accuracy. Scored data were provided to a third investigator, who was blinded to the interventions, for analysis. Data distributions from all outcome measures were inspected before analysis to guide selection of appropriate statistical methods.

\section{Statistical Analysis}

Statistical methods were selected that used all available longitudinal data (i.e., participants' data were included in statistical models even if study participants were unable to or elected not to complete the study per the original protocol). Mixed-effects linear regression modeling was employed to evaluate the effects of the active, adaptive, and passive knee control on measured outcomes. A mixed-effects model was selected because it can account for the correlations among repeated measurements that may otherwise lead to overly conservative $p$-values during statistical hypothesis testing. Moreover, mixed-effects models can maximize power by accounting and adjusting for the within-participant correlations often present in studies with smaller sample sizes [91].

The mixed-effects model was composed of random effects (i.e., individual participants) and fixed effects (i.e., time and knee). Marginal (i.e., model predicted) means in the measured outcomes were derived from the model by phase (i.e., baseline or intervention) and type of intervention knee control (i.e., active or adaptive). Given the complexity of the longitudinal randomized crossover study design, we assessed and controlled for multiple potentially biasing effects (i.e., order, practice). Differences in marginal means between each pair of knee conditions (i.e., active vs passive, adaptive vs passive, and active vs adaptive) were evaluated in terms of magnitude and statistical significance.

The largely dichotomous nature of the falls data (i.e., most subjects reported one or no falls during each observation period) did not lend itself to the linear mixedmodel approach used for other performance-based and self-report outcome measures. Instead, the total number of falls per total number of ( $7 \mathrm{~d}$ ) observation periods was calculated and reported for each knee condition.

All statistical analyses were conducted with Stata/IC 12.1 (StataCorp LP; College Station, Texas). Thresholds for statistically significant differences were set a priori to 0.05 .

\section{RESULTS}

Forty individuals with TFA expressed interest in participating in the study and were screened by telephone. Nineteen people met the basic study selection criteria and were invited for in-laboratory screening. Twelve people met the complete study selection criteria and elected to participate in the study. Table 1 presents a detailed demographic and anthropometric description of the participants enrolled in the trial. All study participants were male, with ages ranging from 49 to $63 \mathrm{yr}$ (mean $\pm \mathrm{SD}=$ $58.8 \pm 6.1)$. All participants reported TFA due to trauma $(83.3 \%)$ or tumor $(16.7 \%)$, with time since amputation ranging from 4 to $44 \mathrm{yr}$ (mean $\pm \mathrm{SD}=28.9 \pm 12.5)$.

Three participants completed the study (i.e., two baseline and two intervention phases) per protocol. Seven additional participants completed at least one baseline and one intervention phase per protocol. Participants that did not complete both intervention phases $(n=7)$ either requested early transition from the knee with the active control system to a subsequent baseline phase $(n=4)$ or voluntarily withdrew from the study $(n=3)$. Not all participants provided reasons for their request to transition early to the adaptive knee or withdraw from the study after use of the active knee. Reasons provided by those participants who provided feedback included knee weight, knee noise, back pain attributed to use of the 
Table 1.

Demographic and anthropometric description of study participants. All participants were male. All participants experienced amputation due to trauma, except for participants 4 and 11 who experienced amputation due to tumor.

\begin{tabular}{|c|c|c|c|c|c|c|}
\hline $\begin{array}{l}\text { Participant } \\
\text { Number }\end{array}$ & $\begin{array}{l}\text { Weight, } \\
\text { lb (kg) }\end{array}$ & Age (yr) & $\begin{array}{c}\text { Time Since } \\
\text { Amputation (yr) }\end{array}$ & SCS & $\begin{array}{c}\text { Prosthetic Knee } \\
\text { (Passive) }\end{array}$ & $\begin{array}{l}\text { Limb Length, in. } \\
\text { (cm) }\end{array}$ \\
\hline 1 & $160(72.6)$ & 63 & 43 & 7 & Össur Mauch SNS & $11.0(28.0)$ \\
\hline 2 & $180(81.6)$ & 60 & 24 & 8 & Össur Mauch SNS & $10.6(27.0)$ \\
\hline 3 & $254(115.2)$ & 54 & 29 & 8 & Ottobock 3R60 & $4.9(12.5)$ \\
\hline 4 & $214(97.1)$ & 63 & 4 & 8 & Össur Total Knee 1900 & $8.3(21.0)$ \\
\hline 5 & $204(92.5)$ & 57 & 33 & 8 & Össur Total Knee 2000 & $11.0(28.0)$ \\
\hline 7 & $198(89.8)$ & 73 & 36 & 9 & Ottobock 3R80 & $4.7(12.0)$ \\
\hline 8 & $228(103.4)$ & 61 & 44 & 8 & DAW TGK-5PS0 & $9.8(25.0)$ \\
\hline 9 & $165(74.8)$ & 49 & 15 & 8 & Össur Mauch SNS & $9.8(25.0)$ \\
\hline 10 & $155(70.3)$ & 55 & 35 & 7 & Ottobock 3R60 & $14.2(36.0)$ \\
\hline 11 & $225(102.1)$ & 57 & 15 & 8 & Ottobock 3R80 & $9.4(24.0)$ \\
\hline
\end{tabular}

knee, unexpected knee behavior (e.g., extension), and challenges getting the knee to enter various modes of operation (e.g., sitting, stair climbing, kneeling). There were no significant differences in weight, age, time since amputation, SCS, or limb length ( $p>0.05$ across all variables) between participants who wore the knee with active control for at least $1 \mathrm{mo}$ and those who requested early transition or withdrew from the study. Two participants were withdrawn from the study by the investigators - one participant after experiencing a medical condition that prohibited continued participation in the study and another because of noncompliance with the evaluation schedule. All data collected from study participants were used to conduct the described analyses (Table 2).

Outcomes associated with laboratory-based performance tests (i.e., TUG, TST, and TRT) were differentially affected by knee-control system (Table 3). Participants' performance-based outcomes were generally unchanged in the knee with adaptive control compared with passive control, with two notable exceptions. Participants' TUGComf and TRT times were significantly reduced (difference $=-0.91 \mathrm{~s}, p<0.001)$ and increased (difference $=$ $0.90 \mathrm{~s}, p=0.02$ ), respectively, in the adaptive control condition. This indicates that while participants completed the TUG-Comf quicker with adaptive control than with passive control, they required more time to ascend and descend the ramp. Performance of laboratory-based tests was generally impaired when participants used the knee with active control. Participants showed significantly increased TUG-Fast (difference $=3.02 \mathrm{~s}, p<0.001$ ), TUG-Comf (difference $=2.66 \mathrm{~s}, p<0.001$ ), and TRT (difference $=0.96 \mathrm{~s}, p=0.03$ ) times with active compared with passive control. This suggests that participants required more time to complete all laboratory-based walking tests, except for the TST, in the motorized knee. Comparison between the active and adaptive conditions also showed significant differences in TUG-Fast and TUGComf times (difference $=3.24$ and $3.56 \mathrm{~s}$, respectively, $p<0.001$ ), suggesting basic mobility (as measured by the TUG) was enhanced with adaptive control.

Outcomes associated with out-of-laboratory walking ability (i.e., OC, VAS-P, VAS-M, RPE, and step activity) were not largely affected by knee-control system (Table 4). No significant differences in OC time or self-reported exertion (physical or mental) were identified between the studied knee conditions. Step activity in the active knee condition, however, was significantly limited compared with the passive knee (difference $=-262$ steps, $p=$ 0.058 ) and adaptive knee (difference $=459$ steps, $p=$ 0.01 ). This suggests that participants took approximately 12 and 20 percent fewer steps in the active knee each day, compared with the passive knee and adaptive knee, respectively.

Few differences in self-report outcomes were observed between the knee conditions (Table 5). Participants 
Table 2.

Data collected by participant, in months and number of observations. " 0 mo" of data collection indicates participant did not use knee in that phase of study (e.g., participant withdrew from study prior to entering that phase). " $<1$ mo" indicates participant was fit with knee but elected to terminate participation in that phase of study (or study entirely) before data were collected.

\begin{tabular}{|c|c|c|c|c|c|c|c|c|}
\hline \multirow{2}{*}{$\begin{array}{l}\text { Participant } \\
\text { Number }\end{array}$} & \multicolumn{4}{|c|}{$\begin{array}{c}\text { Mo of Data Collected } \\
\text { (Maximum Possible Mo of Data) }\end{array}$} & \multicolumn{4}{|c|}{$\begin{array}{c}\text { Number of Obs } \\
\text { (Maximum Possible Obs) }\end{array}$} \\
\hline & $\begin{array}{l}\text { Passive } \\
(1 \mathrm{mo})\end{array}$ & $\begin{array}{l}\text { Adaptive } \\
\text { (6 mo) }\end{array}$ & $\begin{array}{l}\text { Passive } \\
(1 \mathrm{mo})\end{array}$ & $\begin{array}{l}\text { Active } \\
(6 \text { mo })\end{array}$ & $\begin{array}{l}\text { Passive } \\
\text { (4 Obs) }\end{array}$ & $\begin{array}{l}\text { Adaptive } \\
\text { (6 Obs) }\end{array}$ & $\begin{array}{l}\text { Passive } \\
\text { (4 Obs) }\end{array}$ & $\begin{array}{l}\text { Active } \\
\text { (6 Obs) }\end{array}$ \\
\hline$\overline{1}$ & 1 & 6 & 1 & 6 & 4 & 6 & 4 & 6 \\
\hline 2 & 1 & 6 & 1 & $<1$ & 4 & 6 & 4 & 0 \\
\hline 3 & 1 & 6 & 1 & 3 & 4 & 6 & 4 & 3 \\
\hline 4 & 1 & 5 & 1 & 6 & 4 & 5 & 4 & 6 \\
\hline 5 & 1 & 6 & 1 & 6 & 4 & 6 & 4 & 6 \\
\hline 6 & 1 & 6 & 1 & $<1$ & 4 & 6 & 3 & 0 \\
\hline 7 & 1 & 6 & 1 & 3 & 4 & 6 & 4 & 3 \\
\hline 8 & 1 & 5 & 1 & $<1$ & 4 & 5 & 4 & 0 \\
\hline 9 & 1 & 6 & 1 & $<1$ & 4 & 6 & 0 & 0 \\
\hline 10 & 1 & 0 & 1 & $<1$ & 4 & 0 & 0 & 0 \\
\hline 11 & 1 & $<1$ & 0 & 0 & 4 & 0 & 0 & 0 \\
\hline 12 & 1 & 6 & 1 & $<1$ & 4 & 6 & 4 & 0 \\
\hline Totals & 12 & 58 & 11 & 24 & 48 & 58 & 35 & 24 \\
\hline
\end{tabular}

Table 3.

In-laboratory performance-based outcomes by phase and knee condition.

\begin{tabular}{|c|c|c|c|c|c|c|}
\hline \multirow{2}{*}{$\begin{array}{l}\text { Outcome } \\
\text { Measure }\end{array}$} & \multirow[b]{2}{*}{ Study Phase } & \multirow{2}{*}{$\begin{array}{l}\text { Active } \\
\text { Mean }\end{array}$} & \multirow{2}{*}{$\begin{array}{l}\text { Adaptive } \\
\text { Mean }\end{array}$} & \multicolumn{3}{|c|}{ Active vs Adaptive } \\
\hline & & & & Difference & $\begin{array}{c}\mathrm{SE} \\
\text { (Difference) }\end{array}$ & $\begin{array}{c}p \text {-Value } \\
\text { (Difference) }\end{array}$ \\
\hline \multirow{5}{*}{ TUG-Fast, s } & Baseline & 8.96 & 8.87 & -0.09 & 0.20 & 0.64 \\
\hline & Intervention & 11.98 & 8.65 & -3.33 & 0.23 & $<0.001$ \\
\hline & Change & 3.02 & -0.22 & -3.24 & 0.31 & $<0.001$ \\
\hline & SE (Change) & 0.23 & 0.20 & - & - & - \\
\hline & $p$-Value (Change) & $<0.001$ & 0.27 & - & - & - \\
\hline \multirow[t]{5}{*}{ TUG-Comf, s } & Baseline & 11.05 & 11.50 & 0.45 & 0.28 & 0.10 \\
\hline & Intervention & 13.70 & 10.59 & -3.11 & 0.32 & $<0.001$ \\
\hline & Change & 2.66 & -0.91 & -3.56 & 0.43 & $<0.001$ \\
\hline & SE (Change) & 0.32 & 0.28 & - & - & - \\
\hline & $p$-Value (Change) & $<0.001$ & 0.001 & - & - & - \\
\hline \multirow[t]{5}{*}{ TST, s } & Baseline & 15.27 & 14.53 & -0.75 & 0.42 & 0.08 \\
\hline & Intervention & 15.44 & 14.08 & -1.36 & 0.49 & 0.006 \\
\hline & Change & 0.17 & -0.44 & -0.61 & 0.66 & 0.36 \\
\hline & SE (Change) & 0.50 & 0.43 & - & - & - \\
\hline & $p$-Value (Change) & 0.74 & 0.30 & - & - & - \\
\hline \multirow[t]{5}{*}{ TRT, s } & Baseline & 16.01 & 14.69 & -1.32 & 0.36 & $<0.001$ \\
\hline & Intervention & 16.97 & 15.58 & -1.39 & 0.43 & 0.001 \\
\hline & Change & 0.96 & 0.90 & -0.06 & 0.58 & 0.91 \\
\hline & SE (Change) & 0.43 & 0.37 & - & - & - \\
\hline & $p$-Value (Change) & 0.03 & 0.02 & - & - & - \\
\hline
\end{tabular}


Table 4.

Out-of-laboratory performance-based outcomes (and self-report outcomes related to OC) by phase and knee condition.

\begin{tabular}{|c|c|c|c|c|c|c|}
\hline \multirow{2}{*}{$\begin{array}{l}\text { Outcome } \\
\text { Measure }\end{array}$} & \multirow{2}{*}{$\begin{array}{l}\text { Study } \\
\text { Phase }\end{array}$} & \multirow{2}{*}{$\begin{array}{l}\text { Active } \\
\text { Mean }\end{array}$} & \multirow{2}{*}{$\begin{array}{l}\text { Adaptive } \\
\text { Mean }\end{array}$} & \multicolumn{3}{|c|}{ Active vs Adaptive } \\
\hline & & & & Difference & $\begin{array}{c}\mathrm{SE} \\
\text { (Difference) }\end{array}$ & $\begin{array}{c}p \text {-Value } \\
\text { (Difference) }\end{array}$ \\
\hline \multirow{4}{*}{$\overline{\mathrm{OC}}, \mathrm{s}$} & Baseline & 24.80 & 22.61 & -2.19 & 0.74 & 0.003 \\
\hline & Change & -0.42 & 1.04 & 1.47 & 1.16 & 0.21 \\
\hline & SE (Change) & 0.87 & 0.75 & & & \\
\hline & $p$-Value (Change) & 0.62 & 0.16 & & & \\
\hline & Intervention & 61.41 & 62.05 & 0.64 & 4.12 & 0.88 \\
\hline & Change & 3.24 & 4.88 & 1.64 & 5.50 & 0.77 \\
\hline & SE (Change) & 4.14 & 3.57 & & & \\
\hline & $p$-Value (Change) & 0.43 & 0.17 & & & \\
\hline \multirow[t]{2}{*}{ VAS-M, 0-100 } & Baseline & 58.91 & 58.16 & -0.75 & 2.85 & 0.79 \\
\hline & Intervention & 60.57 & 61.98 & 1.41 & 3.35 & 0.67 \\
\hline \multirow[t]{5}{*}{ RPE, 0-120 } & Baseline & 57.01 & 54.58 & -2.43 & 3.18 & 0.44 \\
\hline & Intervention & 60.05 & 58.75 & -1.31 & 3.72 & 0.73 \\
\hline & Change & 3.04 & 4.17 & 1.13 & 4.97 & 0.82 \\
\hline & SE (Change) & 3.74 & 3.23 & & & \\
\hline & $p$-Value (Change) & 0.42 & 0.20 & & & \\
\hline \multirow{5}{*}{$\begin{array}{l}\text { Step Activity, } \\
\text { mean daily steps }\end{array}$} & Baseline & 2204.42 & 2041.37 & -163.04 & 117.95 & 0.17 \\
\hline & Intervention & 1942.49 & 2238.86 & 296.37 & 137.62 & 0.03 \\
\hline & Change & -261.93 & 197.49 & 459.41 & 184.93 & 0.01 \\
\hline & SE (Change) & 138.42 & 119.99 & & & \\
\hline & $p$-Value (Change) & 0.058 & 0.10 & & & \\
\hline
\end{tabular}

reported significantly higher physical function (difference $=$ $1.26, p<0.03)$ after transitioning to a knee with adaptive control from passive control. This suggests that overall daily function was improved with adaptive control. Participants also reported significantly improved balance confidence (difference $=3.77, p=0.003$ ) moving from passive control to active control. This indicates participants felt more confident in their ability to safely perform basic daily activities when wearing the motorized knee. No significant differences in fatigue, mobility, physical (global) health, or mental (global) health were found between any of the studied knee conditions.

Participants' number of reported falls appeared to be negatively affected by both active and adaptive control systems (Table 6). Fall rates (i.e., number of falls per week of observation) in the passive knee condition ranged between 9 and 10 percent. After transition to the adaptive and active knee conditions, fall rates increased to 20 and 40 percent, respectively. This suggests that participants (across the sample) fell 2-4 times as frequently while wearing the knees with adaptive or active control. As noted, no statistical analysis of the falls data was performed.

Eight participants were offered the opportunity to keep the knee with active control or the knee with adaptive control after the study was complete. All eight opted to keep the knee with adaptive control in their primary prosthesis.

\section{DISCUSSION}

This study was designed to evaluate and compare outcomes associated with three different prosthetic kneecontrol systems (i.e., passive, adaptive, and active) in persons with TFA. The knees included in this study are based on three fundamentally different technologies. Knees with passive control, like those used during the baseline phases of the study, offer mechanical (or fluidic) 
JRRD, Volume 52, Number 6, 2015

Table 5.

Self-report outcomes by phase and knee condition.

\begin{tabular}{|c|c|c|c|c|c|c|}
\hline \multirow{2}{*}{$\begin{array}{l}\text { Outcome } \\
\text { Measure }\end{array}$} & \multirow{2}{*}{$\begin{array}{l}\text { Study } \\
\text { Phase }\end{array}$} & \multirow{2}{*}{$\begin{array}{l}\text { Active } \\
\text { Mean }\end{array}$} & \multirow{2}{*}{$\begin{array}{l}\text { Adaptive } \\
\text { Mean }\end{array}$} & \multicolumn{3}{|c|}{ Active vs Adaptive } \\
\hline & & & & Difference & $\begin{array}{c}\text { SE } \\
\text { (Difference) }\end{array}$ & $\begin{array}{c}p \text {-Value } \\
\text { (Difference) }\end{array}$ \\
\hline \multirow[t]{5}{*}{ PEQ-MS, 0-4 } & Baseline & 2.89 & 3.09 & 0.20 & 0.06 & $<0.001$ \\
\hline & Intervention & 2.94 & 3.15 & 0.21 & 0.07 & 0.002 \\
\hline & Change & 0.05 & 0.06 & 0.01 & 0.90 & 0.91 \\
\hline & SE (Change) & 0.07 & 0.06 & & & \\
\hline & $p$-Value (Change) & 0.47 & 0.31 & & & \\
\hline \multirow[t]{5}{*}{ ABC, $0-100$} & Baseline & 78.53 & 83.29 & 4.76 & 1.09 & $<0.001$ \\
\hline & Intervention & 82.31 & 84.47 & 2.16 & 1.27 & 0.09 \\
\hline & Change & 3.77 & 1.18 & -2.60 & 1.70 & 0.13 \\
\hline & SE (Change) & 1.28 & 1.10 & & & \\
\hline & $p$-Value (Change) & 0.003 & 0.28 & & & \\
\hline \multirow[t]{5}{*}{ PROMIS-PF, T-score } & Baseline & 42.92 & 43.48 & 0.56 & 0.57 & 0.33 \\
\hline & Intervention & 42.96 & 44.74 & 1.78 & 0.67 & 0.008 \\
\hline & Change & 0.04 & 1.26 & 1.21 & 0.90 & 0.18 \\
\hline & SE (Change) & 0.67 & 0.58 & & & \\
\hline & $p$-Value (Change) & 0.95 & 0.03 & & & \\
\hline \multirow[t]{5}{*}{ PROMIS-FAT, T-score } & Baseline & 48.27 & 46.66 & -1.61 & 0.79 & 0.04 \\
\hline & Intervention & 46.75 & 47.24 & 0.49 & 0.92 & 0.60 \\
\hline & Change & -1.52 & 0.58 & 2.09 & 1.24 & 0.09 \\
\hline & SE (Change) & 0.93 & 0.80 & & & \\
\hline & $p$-Value (Change) & 0.10 & 0.47 & & & \\
\hline \multirow[t]{5}{*}{ PROMIS-G-PH, T-score } & Baseline & 48.51 & 49.68 & 1.16 & 0.83 & 0.16 \\
\hline & Intervention & 48.74 & 50.05 & 1.31 & 0.97 & 0.18 \\
\hline & Change & 0.23 & 0.37 & 0.15 & 1.30 & 0.91 \\
\hline & SE (Change) & 0.98 & 0.84 & & & \\
\hline & $p$-Value (Change) & 0.82 & 0.66 & & & \\
\hline \multirow[t]{5}{*}{ PROMIS-G-MH, T-score } & Baseline & 52.70 & 52.45 & -0.25 & 0.78 & 0.75 \\
\hline & Intervention & 53.33 & 52.78 & -0.55 & 0.91 & 0.55 \\
\hline & Change & 0.63 & 0.33 & -0.29 & 1.22 & 0.81 \\
\hline & SE (Change) & 0.92 & 0.79 & & & \\
\hline & $p$-Value (Change) & 0.49 & 0.67 & & & \\
\hline
\end{tabular}

resistance to knee flexion or extension that is preset by the user's prosthetist [30]. Knee resistance to flexion and/ or extension may change slightly based on the user walking speed (because of the speed-dependent properties of hydraulic and pneumatic fluids), but the general behavior of the knee will remain constant. Knees with adaptive control, such as the Össur Rheo Knee II used in the intervention phases of this study, constantly adjust knee resistance to flexion and extension, based on data obtained
Table 6.

Self-reported falls by phase and knee condition. Falls are presented as ratio of total number of falls over total number of observation periods. (Note: each fall observation period is $7 \mathrm{~d}$ in length).

\begin{tabular}{cccc}
$\begin{array}{c}\text { Outcome } \\
\text { Measure }\end{array}$ & \multicolumn{1}{c}{$\begin{array}{c}\text { Study } \\
\text { Phase }\end{array}$} & $\begin{array}{c}\text { Active } \\
\text { Condition } \\
\text { Mean }\end{array}$ & $\begin{array}{c}\text { Adaptive } \\
\text { Condition } \\
\text { Mean }\end{array}$ \\
\hline Falls* & Baseline & $4 / 43(9.3)$ & $5 / 40(12.5)$ \\
& Intervention & $10 / 24(41.7)$ & $12 / 58(20.7)$ \\
\hline *Falls = number of falls/number of observation periods (\%). \\
\hline \hline
\end{tabular}


from intrinsic physical sensors. As such, knees with adaptive control systems can adapt their behavior to be more responsive to a user's instantaneous needs. Knees with active control, such as the Össur Power Knee II, are also adaptive in that they utilize data from sensors to dictate knee behavior. The active control system can additionally flex or extend the knee under power to facilitate standing, sitting, and moving [32]. Given the increasingly sophisticated technologies in these knees (going from passive to adaptive to active control), user outcomes, such as mobility, physical function, activity, balance, and safety were expected to progressively improve as users transitioned from a "lower" technology (i.e., passive knee control) to a "higher" one (e.g., adaptive or active knee control).

In general, results of the study do not support the hypotheses that active and adaptive knee control significantly improve physical performance and self-report outcomes among middle-age or older people with TFA compared with passive knee control. Hypotheses were confirmed only in regards to select outcomes. For example, the adaptive knee was found to significantly improve both TUG-Comf performance and participants' perception of their physical function when compared with passive knee control. Other outcomes were not significantly affected by the transition from passive to adaptive knee control. Participants reported significantly improved balance confidence when using the active knee, but experienced significantly worse physical performance on the TUG and TRT. Other outcomes were not significantly affected. Also contrary to hypotheses, the active knee did not significantly improve physical performance in activities that normally require, and would likely benefit from, the positive knee work provided by the active control system (e.g., sit-to-stand, ramp and stair ascent, and distance walking). Ultimately, all participants who completed the study elected to keep the knee with adaptive control in their prosthesis. This may suggest that users benefited from adaptive control in ways that were not detected by measures included in this study.

\section{Laboratory Performance Outcomes}

Physical performance measures are often used as tools to evaluate individual performance in a controlled setting such as a clinic or laboratory. It has been well established that persons with TFA demonstrate diminished performance in many clinical performance-based tests. For example, persons with TFA have demonstrated longer TUG times (i.e., $28.3 \mathrm{~s}$ ) compared with persons with transtibial amputation ( $23.8 \mathrm{~s})$ or elderly peers $(8.5 \mathrm{~s})$ [56-57]. TUG times measured in this study were much lower than those reported by Schoppen et al., as the sample here included participants who were younger (i.e., $59 \mathrm{yr}$ in the current study vs $72 \mathrm{yr}$ in Schoppen et al.'s study) and had acquired amputations from different etiologies (i.e., $100 \%$ from nondysvascular causes in the current study vs $100 \%$ from dysvascular disease in Schoppen et al.'s study [57]). TUG times in our study were more similar to those obtained by Coelho and colleagues from younger participants with TFA (mean TUG times $=12.7-13.3 \mathrm{~s}$, mean age $=44$ yr) [92].

In general, overall performance of the TUG was enhanced in the knee with adaptive control and significantly diminished in the knee with active control compared with the passive control condition. Improved TUG performance with the adaptive control knee is consistent with studies that have shown improved walking speed [39-42] and postural stability [38] with use of adaptive microprocessor-controlled knees. In context with these findings, it may be that adaptive control facilitates comfortable level-ground walking without significantly restricting sit-to-stand movements. Future research with an instrumented TUG [93] may reveal which subtasks (e.g., sit-to-stand, walking, turning, and stand-to-sit) are most affected by adaptive knee control. Reduced TUG times in the active compared with the passive conditions appear to conflict with reports of increased knee power provided by the Power Knee II reported by Wolf and colleagues [51]. However, data here are corroborated by our participants' spontaneous reports that they were often unable to activate the sit and/or stand functions in the Power Knee II. Thus, in a timed test like the TUG, participants likely had to make multiple attempts to activate the knee mode or they were required to bypass flexing/ extending the active knee and using their sound leg to lower/raise their body. Both situations were observed by the investigators during performance testing. These data collectively suggest that, while a motorized knee effectively provides active extension, it may not be optimally activated or timed to enhance performance of normal sitto-stand activities.

Stair performance showed no significant differences among the knee conditions in this study. Similar stair times between participants in the active and adaptive knee conditions are consistent with results reported by Wolf and colleagues, who observed equivalent stair 
ascent and descent speeds on a 16-step staircase between the Power Knee and the Ottobock C-Leg, a prosthetic knee with an adaptive, hydraulic controller [94]. Conversely, similarities in stair times between the adaptive and passive knee conditions here are in contrast to prior studies that assessed stair function in C-Leg and passive knee users [42,44-45]. A key difference between the present study and prior studies was a focus on gait performance (i.e., time), rather than quality of movement. Given differences in reported results, it may be that users' quality of stair negotiation (i.e., stepping pattern and use of rails for assistance) improves with use of adaptive knee control, but the time required to perform the task remains effectively unchanged. It could be argued that improved gait quality is more desirable than raw speed of stair ascent/descent. However, there may be situations (e.g., negotiating stairs in theaters or sports stadiums) in which speed is an important factor. In the future, investigators may consider combining timed stair tests with measures of gait quality, such as the Stair Assessment Index [44,95], to isolate issues of performance and movement quality.

Interestingly, ramp performance was limited in both active and adaptive knee conditions when compared with participants' passive knees. Results in the adaptive condition contrast a recent study by Highsmith et al., who reported significantly faster ramp (i.e., $16 \mathrm{ft}[4.9 \mathrm{~m}], 5^{\circ}$ incline) descent speeds among C-Leg users compared with their previous passive knees [96]. A potential explanation for this discrepancy may be that the TRT used here assessed both stair ascent and descent, whereas Highsmith et al.'s study included only ramp descent. However, as a recent study by Wolf and colleagues showed that ramp ascent and descent speeds on a $19 \mathrm{ft}(5.75 \mathrm{~m})$, $12^{\circ}$ incline were comparable among adaptive and active knee users [94], such an explanation seems unlikely. Another potential reason for differences may be the greater ramp pitch (i.e., $15^{\circ}$ incline) used in this study. Similarities in ramp performance times between adaptive and active conditions in the present study also confirm those of Wolf and colleagues, who found no significant differences in ramp ascent or descent speeds between the Power Knee and C-Leg [94]. Thus, it may be that adaptive or active knees may similarly restrict users when walking down steeper inclines. Additional research is needed to explore this possibility as the investigators also observed that users' overall quality of gait in using the ramp generally improved (i.e., more symmetrical step- ping pattern and less use of rails for assistance) in the adaptive condition compared with the passive knee condition. Thus, trade offs between motion quality and performance may explain participants' limited TRT performance.

\section{Out-of-Laboratory Performance Outcomes}

Both indoor [46,64] and outdoor [42,44-45] OCs have been used by researchers to examine the effects of knee-control system on walking performance. Here, a $0.5 \mathrm{mi}(880 \mathrm{~m})$ course was used to challenge participants walking abilities over an extended duration and over a wide range of terrain types. Compared with the OC used in this study, previous prosthetic knee intervention studies have used outdoor courses that were shorter (i.e., $125-240 \mathrm{ft}[38-73 \mathrm{~m}])$ and correspondingly included less diverse terrain conditions $[42,44-45]$. Further, the selfreport measures of physical and mental exertion used here were not applied in prior studies. In contrast to significant changes in outdoor walking speed noted by previous authors $[42,45]$ when participants with TFA wore a knee with an adaptive control system, adaptive control in this study did not significantly alter participants' time to complete the walking course (nor did it reduce their perceived physical or mental exertion). Results here are more similar to findings reported by Linberg et al., who found no significant differences in 6 min walk distances in servicemembers who wore both microprocessor (adaptive) and nonmicroprocessor (passive) knees [97]. Thus, it may be that adaptive knee technology is more effective at facilitating walking over shorter distances (i.e., $<250 \mathrm{ft}$ $[75 \mathrm{~m}])$ than walking longer distances (i.e., $>0.5 \mathrm{mi}$ [880 m]). More research would be needed to confirm this hypothesis or identify at what distance adaptive control may be unable to overcome the inherent limitations to walking with a functional disability like TFA. Interestingly, walking course time in the active knee condition was improved compared with the passive and adaptive conditions, although the measured differences were not statistically significant. As few participants were able to fully accommodate the knee with active control, additional research is warranted to determine whether motorized knees can improve long-distance walking.

Monitoring participants' with pedometers, accelerometers, or other sensors has been well established as a means for quantifying out-of-laboratory physical activity [98]. Step counting, which has been used to quantify activity across nondisabled and impaired populations, has 
also been applied to the evaluation of a variety of prosthetic components, including prosthetic knees [44$45,99]$. Step activity of participants in our study $(1,942-$ 2,204 steps/d) was similar to that reported by Stepien and colleagues (i.e., 2,284 steps/d) in a cross-sectional study of prosthetic limb users [15]. Participants were also similar in age (i.e., $59 \mathrm{yr}$ in the current study vs $58 \mathrm{yr}$ in Stepien et al.'s study) and etiology of amputation (i.e., $100 \%$ nondysvascular in the current study and $87 \%$ nondysvascular in Stepien et al.'s study). Although no significant differences were measured, results suggest that use of adaptive knee control may slightly increase activity while active knee control may restrict it. These findings for adaptive and passive control are consistent with those previously reported $[44,99]$. However, activity has not been previously studied with motorized knees. Limited step activity in the active knee condition is unexpected, but is consistent with spontaneous reports from participants that the knee was generally challenging to use on a daily basis. Another reason for users' decreased activity may be the $7.1 \mathrm{lb}(3.2 \mathrm{~kg})$ weight of the active knee compared with $1.5-3.4 \mathrm{lb}(0.7-1.5 \mathrm{~kg})$ typical of an adaptive or passive knee. Although it has been proposed that that positive work generated by powered components offsets their increased weight [100], several participants who elected to discontinue their participation in this study noted weight as one reason for their decision. Thus, despite clinical perceptions that active control of the prosthetic knee may enhance users' ability to walk long distances [33], findings of this study suggest that neither active nor adaptive control systems greatly facilitate walking distances over a wide variety of terrain outdoors.

\section{Self-Report Outcomes}

Self-report outcomes are essential tools for soliciting participants' opinions, perspectives, and experiences. These instruments can be used to measure challenging, abstract, or multidimensional constructs like mobility, balance confidence, and overall health. Here, we applied several robust and reliable instruments that measured a range of health outcomes, including physical function (PROMIS-PF), fatigue (PROMIS-FAT), mobility (PEQMS), balance (ABC), physical health (PROMIS-G-PH), and mental health (PROMIS-G-MH) to assess the effects of the studied knee technologies. Both population-specific (e.g., PEQ-MS) and generic (e.g., ABC) measures were used.
Participants' overall mobility, as measured using the 12-item PEQ-MS (i.e., 2.89-3.09), was slightly above average (i.e., 2.83) for persons with TFA due to trauma [101]. Contrary to our hypotheses, knee condition appeared to have no significant effect on self-reported mobility. Knee control may therefore have little influence on self-reported mobility. As the PEQ-MS includes questions that relate to both transition (e.g., sit-to-stand) and ambulation (e.g., walking down a steep hill) activities [81], it is also possible that a knee-control system may benefit users in a particular situation and limit them in others. For example, users may feel the adaptive knee aids them with sit-to-stand, as evidenced by the significant decrease in TUG-Comf times, but limits them in walking down a steep hill, as evidenced by the significant increase in TRT times compared with the passive knee. As both of these activities are questions in the PEQ-MS, the lack of observed differences in PEQ-MS scores across interventions may be due to offsetting perceptions of mobility in these various activities.

Balance confidence, as measured by the $\mathrm{ABC}$ (range 78-84), was notably higher in all knees in this study compared with average scores reported by Miller and colleagues (i.e., 62.9) for persons with TFA [85]. Higher $\mathrm{ABC}$ scores here are likely the result of the nondysvascular amputation etiologies reported by participants compared with mixed amputation etiologies studied previously. As anticipated, both adaptive and active kneecontrol systems positively affected balance confidence, although only active knee control showed a significant improvement compared with the passive knee condition. Interestingly, these data contrast reported falls. In combination, these data indicate participants experienced more frequent falls, despite their increased confidence in the active knee. This may suggest that increased confidence may have inspired users to attempt activities that resulted in a fall.

PROMIS instruments were used to evaluate physical function, fatigue, and general health (physical and mental). Both physical function and fatigue (i.e., range $42-43$ and 46-48, respectively) among the studied participants were consistent with norms for persons with TFA from trauma (42 and 47, respectively) [74]. Perceived physical function was significantly improved with use of the adaptive control system, but unaffected with the active system. Conversely, reported fatigue was mitigated when participants wore the knee with the active control, but slightly elevated when the prosthesis included adaptive 
knee control. However, neither effect was significantly different from the knee with passive control. As anticipated, participants' overall physical and mental health was, on average, unchanged over the duration of the study. Thus, the type of knee control was likely responsible for changes observed in the study sample across the measured outcomes.

\section{Falls}

Falls are a serious health issue for many individuals with physical impairments, including those with TFA. More than two-thirds of people with TFA report experiencing a fall at least once per year $[12,102]$. Further, injuries associated with falls are nearly twice as common in people with TFA than nondisabled elderly adults $[12,103-104]$. Therefore, interventions that may reduce risks of falls and associated injuries, such as advanced prosthetic knee technologies, warrant investigation.

Contrary to expectations, participants in this study reported an increased frequency of falling when wearing both adaptive and active knee systems compared with a knee with a passive control system. This finding is in contrast to other studies that have reported decreased falling with use of other adaptive prosthetic knee systems $[42,44-45]$. One possible explanation for this discrepancy is the type of prosthetic knee used in these studies. Previous studies used a knee with adaptive control of a hydraulic piston in contrast to the adaptive MR system and active motor system included in the knees in this study. It has been suggested that adaptive control of a (linear) hydraulic piston is inherently stable and may therefore resist knee collapse [30]. The adaptive system used in this study includes an MR shear mode system that can rapidly change resistance, but may not resist stumbles as effectively as a linear hydraulic system. An alternative explanation for the study results in contrast to prior studies may be differences in participant populations. Participants in previous studies were, on average, about $10 \mathrm{yr}$ younger than those in this study [42,44-45]. It may be that older users do not benefit from the fall prevention technologies inherent to these knees or that they may require additional time to master the techniques necessary to use them.

\section{Limitations}

Potential limitations to this study include participant variations in the passive knee condition, reliability of selected outcome measures, blinding of investigators to the interventions, a relatively small sample size, and attrition of study subjects.

Participants were assessed in the baseline phases of the study while wearing their own prosthetic knees with a passive control system. While these knees are collectively classified as "passive" according to a recently proposed knee-classification system [27], there are variations in the mechanical features of the passive knees used by study participants. For example, participants began the study wearing single-axis hydraulic $(n=6)$, polycentric hydraulic $(n=4)$, polycentric pneumatic $(n=1)$, and polycentric friction $(n=1)$ knees (Table 1). While these knees are all based on passive mechanical or fluidic control systems, there may be differences in function that confound results in the baseline phase of the study. The decision to assess participants with their existing components is common in prosthetics research and is reflective of clinical practice [55].

As noted previously, participants were provided training to use the adaptive and active knees as part of the study procedures. However, training was not provided to participants in the baseline phase of the study (i.e., while they wore the passive knee). Presumably, participants were trained to use their prostheses by their own prosthetists and/or physical therapists prior to the study. Gait training is part of the standard of care provided to most prosthetic users [105]. However, the type and extent of training may have varied among participants. In order to minimize this source of variation, participants were screened by a prosthetist prior to inclusion in the study to ensure they were capable ambulators and could complete all study procedures.

Here, a suite of clinically relevant instruments was used to study participant outcomes. Several outcome measures (e.g., TUG, PEQ-MS) included in this study are standardized instruments with evidence of reliability and/ or validity with persons with lower-limb loss. Others were adapted from existing instruments (e.g., TRT, TST) or developed exclusively for this study (e.g., OC). Thus, psychometric properties of these instruments (e.g., reliability, validity, responsiveness) may be unknown. Although many outcome measures in lower-limb prosthetics lack desirable psychometric evidence, use of those with limited evidence is recommended in prosthetics research in the absence of better alternatives [58]. The investigators hoped that including a range of physical performance and self-report outcomes would allow for a 
comprehensive and fair assessment of the knees under study.

Although attempts were made to blind study participants and the investigator performing the analyses to the interventions under study, the prosthetist who administered the physical performance measures to participants was aware of the interventions. Thus, there exists the potential for implicit bias in results from physical performance tests. Blinding or masking the instrument administrator was deemed impractical as the active knee could be identified by an observer when masked (i.e., the knee's motor is clearly audible from a short distance). To mitigate concerns of investigator bias, we required all investigators to report that they had no personal or financial conflicts of interest with the studied interventions or results.

Although small samples may limit generalizability of the study findings, small samples are common in rehabilitation research [106]. This is especially true in studies related to advanced prosthetic components in which the cost of purchasing components for large numbers of participants can be prohibitive. Experimental studies that include providing microprocessor-controlled prosthetic knees to participants, for example, have typically included fewer than 10 subjects [37]. Here, the investigators attempted to maximize data that could be collected from a relatively small sample of participants. Features of the study design included repeated measures, randomization of intervention assignment, crossover, and repetition to obtain as much data as possible from participants over the study period. The robust statistical analysis further allowed us to use all available data to examine differences between the studied prosthetic knee systems.

Of the 12 participants who were recruited, 10 (83\%) completed a substantial portion of the study (i.e., the intervention phase that included the knee with adaptive control), but only 3 (25\%) completed the study per protocol (i.e., both interventions and all data collection sessions). Reasons for not completing the full protocol or for withdrawing from the study were most often attributed to participants' difficulties adapting to the motorized knee. Despite the training provided, most participants were unable to fully utilize all motorized knee functions, as evidenced by the diminished performance across study outcomes (e.g., stair ascent/descent in the TST). Participants' opinions of the knees were also reflected in their choice to keep the knee with adaptive control in their prosthesis over the motorized (or passive) knee after the study was completed.
The limited number of participants who elected to complete the intervention phase while wearing the knee with the active control system also resulted in an unbalanced study design. Although an unbalanced design may lead to biased or unstable estimates [91], a post hoc comparison of differences in raw means from separate univariate models (data not presented) indicated that the mixed-effects model led to slightly more conservative estimates of the difference between knee conditions. The mixed-effects approach used here was therefore deemed most appropriate, given the limitations of the available data.

Lastly, outcomes measured in this study were obtained from two specific versions of the Össur Rheo Knee II and Power Knee II. To maintain experimental control, knees were not updated or modified as new versions or firmware became available. For example, a new version of the Rheo Knee (i.e., Rheo Knee III) and an updated firmware for the Power Knee II were made available by the manufacturer during the study period, but those updates were not applied. Thus, findings reported here may not generalize to newer versions of these knees or to other models of knees that include adaptive or active control systems. Initial evidence suggests that use of the Rheo Knee III may improve mobility, walking distance, perceived effort, and perceived quality of life compared with other knees with adaptive and passive control [107-108]. Additional research is needed to determine whether the technological changes inherent in the Rheo III affect the long-term outcomes studied here.

\section{CONCLUSIONS}

The findings of this study indicate that advanced prosthetic knee technologies, such as those based on adaptive and active control systems, differentially affect middle-aged and older prosthetic users compared with knees with passive control systems. Adaptive knee control, as implemented in the Össur Rheo Knee II, significantly improved users' mobility at self-selected walking speed and perceived function in daily activities, but limited the speed with which they ascend and descend ramps. That the knee with adaptive control was ultimately selected by all users who experienced the studied knee technologies suggests that walking speed or perceived function were important factors in their choice or that outcomes that showed nonsignificant improvements (e.g., fast walking speeds, stair ascent/descent, or step activity) 
may be perceptible. Together, these data indicate that prosthetic knees with adaptive control may be a functional and desirable intervention for middle-age or older TFA prosthetic users. Active knee control, as found the Össur Power Knee II, significantly limited users laboratorybased mobility and overall daily activity. Users' longdistance walking ability and perceived mobility, function, and health were comparable between knees with active and passive control. However, generally poor outcomes and high attrition of subjects in the active knee condition suggest that active knee control, as it is implemented in the Power Knee II, may not be ideal for middle-age or older persons with TFA.

\section{ACKNOWLEDGMENTS}

\author{
Author Contributions: \\ Study concept and design: B. J. Hafner. \\ Analysis and interpretation of data: R. L. Askew, B. J. Hafner. \\ Drafting of manuscript: B. J. Hafner. \\ Critical revision of manuscript for important intellectual content: \\ R. L. Askew, B. J. Hafner. \\ Statistical analysis: R. L. Askew.
}

Financial Disclosures: This research was supported by an institutional research grant from Össur hf (Reykjavík, Iceland). The investigators were responsible for the design, collection, analysis, and interpretation of data; authorship of the manuscript; and decision to submit the manuscript for publication. The study sponsor had no role in study activities. The sponsor was provided a summary of study results and copies of manuscripts submitted for publication.

Funding/Support: This material was based on work supported by an institutional research grant from Össur hf (grant A62089).

Additional Contributions: The authors gratefully acknowledge Matthew Manges, DPT, and Goeran Fiedler, PhD, for assistance with data collection and preliminary analyses. The authors also thank Alyssa Bamer and Dagmar Amtmann for assistance with developing the custom physical function short form and scoring guide. The authors also acknowledge Össur hf for donation of the prosthetic components used in this study.

Institutional Review: A University of Washington Institutional Review Board approved all study procedures.

Participant Follow-Up: The authors do not intend to notify individual participants about this publication because the permissible period to contact participants has expired.

\section{REFERENCES}

1. Fernie GR, Holliday PJ. Postural sway in amputees and normal subjects. J Bone Joint Surg Am. 1978;60(7):89598. [PMID:701337]
2. Geurts AC, Mulder TH. Attention demands in balance recovery following lower limb amputation. J Mot Behav. 1994;26(2):162-70. [PMID:15753068] http://dx.doi.org/10.1080/00222895.1994.9941670

3. Buckley JG, O’Driscoll D, Bennett SJ. Postural sway and active balance performance in highly active lower-limb amputees. Am J Phys Med Rehabil. 2002;81(1):13-20. [PMID:11807327] http://dx.doi.org/10.1097/00002060-200201000-00004

4. Miller WC, Deathe AB. A prospective study examining balance confidence among individuals with lower limb amputation. Disabil Rehabil. 2004;26(14-15):875-81. [PMID:15497916] http://dx.doi.org/10.1080/09638280410001708887

5. Vrieling AH, van Keeken HG, Schoppen T, Otten E, Hof AL, Halbertsma JP, Postema K. Balance control on a moving platform in unilateral lower limb amputees. Gait Posture. 2008;28(2):222-28. [PMID:18207407] http://dx.doi.org/10.1016/j.gaitpost.2007.12.002

6. Traugh GH, Corcoran PJ, Reyes RL. Energy expenditure of ambulation in patients with above-knee amputations. Arch Phys Med Rehabil. 1975;56(2):67-71. [PMID:1124978]

7. Boonstra AM, Schrama J, Fidler V, Eisma WH. The gait of unilateral transfemoral amputees. Scand J Rehabil Med. 1994;26(4):217-23. [PMID:7878397]

8. Waters RL, Mulroy S. The energy expenditure of normal and pathologic gait. Gait Posture. 1999;9(3):207-31. [PMID: 10575082] http://dx.doi.org/10.1016/S0966-6362(99)00009-0

9. Genin JJ, Bastien GJ, Franck B, Detrembleur C, Willems PA. Effect of speed on the energy cost of walking in unilateral traumatic lower limb amputees. Eur J Appl Physiol. 2008;103(6):655-63. [PMID:18478251] http://dx.doi.org/10.1007/s00421-008-0764-0

10. Jaegers SM, Arendzen JH, de Jongh HJ. Prosthetic gait of unilateral transfemoral amputees: A kinematic study. Arch Phys Med Rehabil. 1995;76(8):736-43. [PMID:7632129] http://dx.doi.org/10.1016/S0003-9993(95)80528-1

11. Donker SF, Beek PJ. Interlimb coordination in prosthetic walking: Effects of asymmetry and walking velocity. Acta Psychol (Amst). 2002;110(2-3):265-88.

[PMID:12102109] http://dx.doi.org/10.1016/S0001-6918(02)00037-9

12. Miller WC, Speechley M, Deathe B. The prevalence and risk factors of falling and fear of falling among lower extremity amputees. Arch Phys Med Rehabil. 2001;82(8): 1031-37. [PMID:11494181] http://dx.doi.org/10.1053/apmr.2001.24295

13. Gauthier-Gagnon C, Grise M, Potvin D. Predisposing factors related to prosthetic use by people with a transtibial 
and transfemoral amputation. J Prosthet Orthot. 1998; 10(4):99-109.

http://dx.doi.org/10.1097/00008526-199801040-00006

14. Holden J, Fernie G. Minimal walking levels for amputees living at home. Physiother Can. 1983;35(6):317-20.

15. Stepien JM, Cavenett S, Taylor L, Crotty M. Activity levels among lower-limb amputees: Self-report versus step activity monitor. Arch Phys Med Rehabil. 2007;88(7): 896-900. [PMID:17601471]

http://dx.doi.org/10.1016/j.apmr.2007.03.016

16. Halsne EG, Waddingham MG, Hafner BJ. Long-term activity in and among persons with transfemoral amputation. J Rehabil Res Dev. 2013;50(4):515-30.

[PMID:23934872]

http://dx.doi.org/10.1682/JRRD.2012.04.0066

17. Jones SF, Twigg PC, Scally AJ, Buckley JG. The mechanics of landing when stepping down in unilateral lowerlimb amputees. Clin Biomech (Bristol, Avon). 2006; 21(2):184-93. [PMID:16274904] http://dx.doi.org/10.1016/j.clinbiomech.2005.09.015

18. Vrieling AH, van Keeken HG, Schoppen T, Otten E, Halbertsma JP, Hof AL, Postema K. Uphill and downhill walking in unilateral lower limb amputees. Gait Posture. 2008;28(2):235-42. [PMID:18242995] http://dx.doi.org/10.1016/j.gaitpost.2007.12.006

19. Vrieling AH, van Keeken HG, Schoppen T, Otten E, Halbertsma JP, Hof AL, Postema K. Obstacle crossing in lower limb amputees. Gait Posture. 2007;26(4):587-94. [PMID:17275306] http://dx.doi.org/10.1016/j.gaitpost.2006.12.007

20. Ramstrand N, Nilsson KA. A comparison of foot placement strategies of transtibial amputees and able-bodied subjects during stair ambulation. Prosthet Orthot Int. 2009;33(4):348-55. [PMID:19961296] http://dx.doi.org/10.3109/03093640903074891

21. Legro MW, Reiber G, del Aguila M, Ajax MJ, Boone DA, Larsen JA, Smith DG, Sangeorzan B. Issues of importance reported by persons with lower limb amputations and prostheses. J Rehabil Res Dev. 1999;36(3):155-63. [PMID:10659798]

22. Hagberg K, Brånemark R. Consequences of non-vascular trans-femoral amputation: A survey of quality of life, prosthetic use and problems. Prosthet Orthot Int. 2001; 25(3):186-94. [PMID:11860092] http://dx.doi.org/10.1080/03093640108726601

23. Pezzin LE, Dillingham TR, MacKenzie EJ. Rehabilitation and the long-term outcomes of persons with trauma-related amputations. Arch Phys Med Rehabil. 2000;81(3):292-300. [PMID:10724073] http://dx.doi.org/10.1016/S0003-9993(00)90074-1

24. Dougherty PJ. Long-term follow-up of unilateral transfemoral amputees from the Vietnam war. J Trauma. 2003;
54(4):718-23. [PMID:12707534]

http://dx.doi.org/10.1097/01.TA.0000046260.16866.A9

25. Ware JE Jr, Sherbourne CD. The MOS 36-item short-form health survey (SF-36). I. Conceptual framework and item selection. Med Care. 1992;30(6):473-83. [PMID:1593914] http://dx.doi.org/10.1097/00005650-199206000-00002

26. Sullivan M, Karlsson J, Ware J. SF-36 Hälsoenkäf. Svensk Manual och tolkingsguide (Swedish Manual and Interpretation guide). Gothenburg (Sweden): Sahlgrenska University Hospital; 1994. Swedish.

27. Berke GM, Geil M. Appendix microprocessor knee manufacturers forum report. J Prosthet Orthot. 2013;25(4S): 80-83. http://dx.doi.org/10.1097/JPO.0b013e3182a750eb

28. Michael JW. Modern prosthetic knee mechanisms. Clin Orthop Relat Res. 1999;(361):39-47. [PMID:10212594]

29. Romo HD. Prosthetic knees. Phys Med Rehabil Clin N Am. 2000;11(3):595-607, vii. [PMID:10989481]

30. Berry D. Microprocessor prosthetic knees. Phys Med Rehabil Clin N Am. 2006;17(1):91-113, vii. [PMID:16517347] http://dx.doi.org/10.1016/j.pmr.2005.10.006

31. Fergason J, Keeling JJ, Bluman EM. Recent advances in lower extremity amputations and prosthetics for the combat injured patient. Foot Ankle Clin. 2010;15(1):151-74. [PMID:20189122] http://dx.doi.org/10.1016/j.fcl.2009.10.001

32. Laferrier JZ, Gailey R. Advances in lower-limb prosthetic technology. Phys Med Rehabil Clin N Am. 2010;21(1): 87-110. [PMID:19951780] http://dx.doi.org/10.1016/j.pmr.2009.08.003

33. Harvey ZT, Potter BK, Vandersea J, Wolf E. Prosthetic advances. J Surg Orthop Adv. 2012;21(1):58-64. [PMID:22381512]

34. Sup F, Bohara A, Goldfarb M. Design and control of a powered transfemoral prosthesis. Int J Rob Res. 2008; 27(2):263-73. [PMID:19898683] http://dx.doi.org/10.1177/0278364907084588

35. Ha KH, Varol HA, Goldfarb M. Volitional control of a prosthetic knee using surface electromyography. IEEE Trans Biomed Eng. 2011;58(1):144-51. [PMID:20805047] http://dx.doi.org/10.1109/TBME.2010.2070840

36. Lawson BE, Ruhe B, Shultz A, Goldfarb M. A powered prosthetic intervention for bilateral transfemoral amputees. IEEE Trans Biomed Eng. 2015;62(4):1042-50. [PMID:25014950]

37. Sawers AB, Hafner BJ. Outcomes associated with the use of microprocessor-controlled prosthetic knees among individuals with unilateral transfemoral limb loss: A systematic review. J Rehabil Res Dev. 2013;50(3):273-314. [PMID:23881757] http://dx.doi.org/10.1682/JRRD.2011.10.0187 
38. Kaufman KR, Levine JA, Brey RH, Iverson BK, McCrady SK, Padgett DJ, Joyner MJ. Gait and balance of transfemoral amputees using passive mechanical and microprocessor-controlled prosthetic knees. Gait Posture. 2007;26(4):489-93. [PMID:17869114] http://dx.doi.org/10.1016/j.gaitpost.2007.07.011

39. Johansson JL, Sherrill DM, Riley PO, Bonato P, Herr H. A clinical comparison of variable-damping and mechanically passive prosthetic knee devices. Am J Phys Med Rehabil. 2005;84(8):563-75. [PMID:16034225] http://dx.doi.org/10.1097/01.phm.0000174665.74933.0b

40. Orendurff MS, Segal AD, Klute GK, McDowell ML, Pecoraro JA, Czerniecki JM. Gait efficiency using the C-Leg. J Rehabil Res Dev. 2006;43(2):239-46. [PMID:16847790] http://dx.doi.org/10.1682/JRRD.2005.06.0095

41. Segal AD, Orendurff MS, Klute GK, McDowell ML, Pecoraro JA, Shofer J, Czerniecki JM. Kinematic and kinetic comparisons of transfemoral amputee gait using C-Leg and Mauch SNS prosthetic knees. J Rehabil Res Dev. 2006;43(7):857-70. [PMID:17436172] http://dx.doi.org/10.1682/JRRD.2005.09.0147

42. Kahle JT, Highsmith MJ, Hubbard SL. Comparison of nonmicroprocessor knee mechanism versus C-Leg on Prosthesis Evaluation Questionnaire, stumbles, falls, walking tests, stair descent, and knee preference. J Rehabil Res Dev. 2008;45(1):1-14. [PMID:18566922] http://dx.doi.org/10.1682/JRRD.2007.04.0054

43. Kaufman KR, Levine JA, Brey RH, McCrady SK, Padgett DJ, Joyner MJ. Energy expenditure and activity of transfemoral amputees using mechanical and microprocessorcontrolled prosthetic knees. Arch Phys Med Rehabil. 2008;89(7):1380-85. [PMID:18586142] http://dx.doi.org/10.1016/j.apmr.2007.11.053

44. Hafner BJ, Willingham LL, Buell NC, Allyn KJ, Smith DG. Evaluation of function, performance, and preference as transfemoral amputees transition from mechanical to microprocessor control of the prosthetic knee. Arch Phys Med Rehabil. 2007;88(2):207-17. [PMID:17270519] http://dx.doi.org/10.1016/j.apmr.2006.10.030

45. Hafner BJ, Smith DG. Differences in function and safety between Medicare Functional Classification Level-2 and -3 transfemoral amputees and influence of prosthetic knee joint control. J Rehabil Res Dev. 2009;46(3):417-33. [PMID:19675993] http://dx.doi.org/10.1682/JRRD.2008.01.0007

46. Seymour R, Engbretson B, Kott K, Ordway N, Brooks G, Crannell J, Hickernell E, Wheeler K. Comparison between the C-leg microprocessor-controlled prosthetic knee and non-microprocessor control prosthetic knees: A preliminary study of energy expenditure, obstacle course performance, and quality of life survey. Prosthet Orthot
Int. 2007;31(1):51-61. [PMID:17365885]

http://dx.doi.org/10.1080/03093640600982255

47. Highsmith MJ, Kahle JT, Carey SL, Derek J, Dubey RV, Quillen WS. Kinetic differences using a Power Knee and C-Leg while sitting down and standing up: A case report. J Prosthet Orthot. 2010;22(4):237-43. http://dx.doi.org/10.1097/JPO.0b013e3181f46b65

48. Herr H, Wilkenfeld A. User-adaptive control of a magnetorheological prosthetic knee. Ind Rob. 2003;30(1):42-55. http://dx.doi.org/10.1108/01439910310457706

49. Bellmann M, Schmalz T, Blumentritt S. Comparative biomechanical analysis of current microprocessor-controlled prosthetic knee joints. Arch Phys Med Rehabil. 2010; 91(4):644-52. [PMID:20382300] http://dx.doi.org/10.1016/j.apmr.2009.12.014

50. Highsmith MJ, Kahle JT, Carey SL, Lura DJ, Dubey RV, Csavina KR, Quillen WS. Kinetic asymmetry in transfemoral amputees while performing sit to stand and stand to sit movements. Gait Posture. 2011;34(1):86-91. [PMID:21524913] http://dx.doi.org/10.1016/j.gaitpost.2011.03.018

51. Wolf EJ, Everding VQ, Linberg AA, Czerniecki JM, Gambel JM. Comparison of the Power Knee and C-Leg during step-up and sit-to-stand tasks. Gait Posture. 2013; 38(3):397-402. [PMID:23375018]

52. U.S. Census Bureau. 2010 Census Briefs-Age and sex composition: 2010 [Internet]. Washington (DC): U.S. Department of Commerce; 2011 [cited 2015 Mar 9]. Available from: http://www.census.gov/prod/cen2010/ briefs/c2010br-03.pdf.

53. Centers for Medicare and Medicaid Services. Medicare region $\mathrm{C}$ durable medical equipment prosthetics orthotic supplier (DMEPOS) manual. Washington (DC): U.S. Department of Health and Human Services; 2005.

54. Hanspal RS, Fisher K, Nieveen R. Prosthetic socket fit comfort score. Disabil Rehabil. 2003;25(22):1278-80. [PMID:14617445] http://dx.doi.org/10.1080/09638280310001603983

55. Hafner BJ, Sawers AB. Issues affecting the level of prosthetics research evidence: Secondary analysis of a systematic review. Prosthet Orthot Int. 2014. Epub ahead of print. [PMID:25249383] http://dx.doi.org/10.1177/0309364614550264

56. Podsiadlo D, Richardson S. The timed "Up \& Go": A test of basic functional mobility for frail elderly persons. J Am Geriatr Soc. 1991;39(2):142-48. [PMID:1991946] http://dx.doi.org/10.1111/j.1532-5415.1991.tb01616.x

57. Schoppen T, Boonstra A, Groothoff JW, de Vries J, Göeken LN, Eisma WH. The Timed "up and go" test: Reliability and validity in persons with unilateral lower limb amputation. Arch Phys Med Rehabil. 1999;80(7): 
825-28. [PMID:10414769]

http://dx.doi.org/10.1016/S0003-9993(99)90234-4

58. Condie E, Scott H, Treweek S. Lower limb prosthetic outcome measures: A review of the literature 1995 to 2005. J Prosthet Orthot. 2006;18(1S):13-45. http://dx.doi.org/ 10.1097/00008526-200601001-00004

59. Barry E, Galvin R, Keogh C, Horgan F, Fahey T. Is the Timed Up and Go test a useful predictor of risk of falls in community dwelling older adults: A systematic review and meta-analysis. BMC Geriatr. 2014;14:14.

[PMID:24484314]

http://dx.doi.org/10.1186/1471-2318-14-14

60. U.S. Department of Justice. Americans with Disabilities Act Title III Regulations: Standards for Accessible Design. 28 C.F.R. Part 36, Appendix A, 2010.

61. Pua YH, Wrigley TV, Collins M, Cowan SM, Bennell KL. Self-report and physical performance measures of physical function in hip osteoarthritis: Relationship to isometric quadriceps torque development. Arthritis Rheum. 2009; 61(2):201-8. [PMID:19177533]

http://dx.doi.org/10.1002/art.24277

62. Kennedy DM, Stratford PW, Hanna SE, Wessel J, Gollish JD. Modeling early recovery of physical function following hip and knee arthroplasty. BMC Musculoskelet Disord. 2006;7:100. [PMID:17156487] http://dx.doi.org/10.1186/1471-2474-7-100

63. Walsh M, Woodhouse LJ, Thomas SG, Finch E. Physical impairments and functional limitations: A comparison of individuals 1 year after total knee arthroplasty with control subjects. Phys Ther. 1998;78(3):248-58.

[PMID:9520970]

64. Meier MR, Hansen AH, Gard SA, McFadyen AK. Obstacle course: Users' maneuverability and movement efficiency when using Otto Bock C-Leg, Otto Bock 3R60, and CaTech SNS prosthetic knee joints. J Rehabil Res Dev. 2012;49(4):583-96. [PMID:22773261] http://dx.doi.org/10.1682/JRRD.2010.05.0094

65. Narang IC, Mathur BP, Singh P, Jape VS. Functional capabilities of lower limb amputees. Prosthet Orthot Int. 1984;8(1):43-51. [PMID:6718238]

66. Geertzen JH, Bosmans JC, van der Schans CP, Dijkstra PU. Claimed walking distance of lower limb amputees. Disabil Rehabil. 2005;27(3):101-4. [PMID:15823990] http://dx.doi.org/10.1080/09638280400009345

67. Borg E, Borg G. A comparison of AME and CR100 for scaling perceived exertion. Acta Psychol (Amst). 2002; 109(2):157-75. [PMID:11820425] http://dx.doi.org/10.1016/S0001-6918(01)00055-5

68. Patrician PA. Single-item graphic representational scales. Nurs Res. 2004;53(5):347-52. [PMID:15385872] http://dx.doi.org/10.1097/00006199-200409000-00011
69. Godfrey A, Conway R, Meagher D, O'Laighin G. Direct measurement of human movement by accelerometry. Med Eng Phys. 2008;30(10):1364-86. [PMID:18996729] http://dx.doi.org/10.1016/j.medengphy.2008.09.005

70. Bassett DR, John D. Use of pedometers and accelerometers in clinical populations: Validity and reliability issues. Phys Ther Rev. 2010;15(3):135-42. http://dx.doi.org/10.1179/1743288X10Y.0000000004

71. Cella D, Riley W, Stone A, Rothrock N, Reeve B, Yount S, Amtmann D, Bode R, Buysse D, Choi S, Cook K, Devellis R, DeWalt D, Fries JF, Gershon R, Hahn EA, Lai JS, Pilkonis P, Revicki D, Rose M, Weinfurt K, Hays R; PROMIS Cooperative Group. The Patient-Reported Outcomes Measurement Information System (PROMIS) developed and tested its first wave of adult self-reported health outcome item banks: 2005-2008. J Clin Epidemiol. 2010;63(11):1179-94. [PMID:20685078] http://dx.doi.org/10.1016/j.jclinepi.2010.04.011

72. PROMIS. PROMIS Instrument development and psychometric evaluation scientific standards. Silver Spring (MD): National Institutes of Health; 2012.

73. Rothrock NE, Hays RD, Spritzer K, Yount SE, Riley W, Cella D. Relative to the general US population, chronic diseases are associated with poorer health-related quality of life as measured by the Patient-Reported Outcomes Measurement Information System (PROMIS). J Clin Epidemiol. 2010;63(11):1195-1204. [PMID:20688471] http://dx.doi.org/10.1016/j.jclinepi.2010.04.012

74. Amtmann D, Morgan SJ, Kim J, Hafner BJ. Healthrelated profiles of people with lower limb loss. Arch Phys Med Rehabil. 2015;96(8):1474-83. [PMID:25917819] http://dx.doi.org/10.1016/j.apmr.2015.03.024

75. Rose M, Bjorner JB, Becker J, Fries JF, Ware JE. Evaluation of a preliminary physical function item bank supported the expected advantages of the Patient-Reported Outcomes Measurement Information System (PROMIS). J Clin Epidemiol. 2008;61(1):17-33. [PMID:18083459] http://dx.doi.org/10.1016/j.jclinepi.2006.06.025

76. Patient-Reported Outcomes Measurement Information System. PROMIS scoring guide: Version 1.0 short forms, profile short forms, computerized adaptive testing [Internet]. Bethesda (MD): National Institutes of Health; 2011. [Accessed May 09, 2013]. Available from: http:// www.assessmentcenter.net/documents/PROMIS Scoring Manual- CATs, Profiles, Short Forms.pdf

77. Cella D, Gershon R, Lai JS, Choi S. The future of outcomes measurement: Item banking, tailored short-forms, and computerized adaptive assessment. Qual Life Res. 2007;16(Suppl 1):133-41. [PMID:17401637] http://dx.doi.org/10.1007/s11136-007-9204-6

78. Hays RD, Bjorner JB, Revicki DA, Spritzer KL, Cella D. Development of physical and mental health summary 
scores from the patient-reported outcomes measurement information system (PROMIS) global items. Qual Life Res. 2009;18(7):873-80. [PMID:19543809] http://dx.doi.org/10.1007/s11136-009-9496-9

79. Miller WC, Deathe AB, Speechley M. Lower extremity prosthetic mobility: A comparison of 3 self-report scales. Arch Phys Med Rehabil. 2001;82(10):1432-40.

[PMID:11588750] http://dx.doi.org/10.1053/apmr.2001.25987

80. Legro MW, Reiber GD, Smith DG, del Aguila M, Larsen $\mathrm{J}$, Boone D. Prosthesis evaluation questionnaire for persons with lower limb amputations: Assessing prosthesisrelated quality of life. Arch Phys Med Rehabil. 1998; 79(8):931-38. [PMID:9710165] http://dx.doi.org/10.1016/S0003-9993(98)90090-9

81. Franchignoni F, Giordano A, Ferriero G, Orlandini D, Amoresano A, Perucca L. Measuring mobility in people with lower limb amputation: Rasch analysis of the mobility section of the prosthesis evaluation questionnaire. J Rehabil Med. 2007;39(2):138-44. [PMID:17351696] http://dx.doi.org/10.2340/16501977-0033

82. Powell LE, Myers AM. The Activities-Specific Balance Confidence (ABC) Scale. J Gerontol A Biol Sci Med Sci. 1995;50A(1):M28-34. [PMID:7814786] http://dx.doi.org/10.1093/gerona/50A.1.M28

83. Asano M, Rushton P, Miller WC, Deathe BA. Predictors of quality of life among individuals who have a lower limb amputation. Prosthet Orthot Int. 2008;32(2):231-43. [PMID:18569891] http://dx.doi.org/10.1080/03093640802024955

84. Deathe AB, Miller WC. The L test of functional mobility: Measurement properties of a modified version of the timed "up \& go" test designed for people with lower-limb amputations. Phys Ther. 2005;85(7):626-35. [PMID:15982169]

85. Miller WC, Deathe AB, Speechley M. Psychometric properties of the Activities-Specific Balance Confidence Scale among individuals with a lower-limb amputation. Arch Phys Med Rehabil. 2003;84(5):656-61. [PMID:12736877]

86. Sakakibara BM, Miller WC, Backman CL. Rasch analyses of the Activities-specific Balance Confidence Scale with individuals 50 years and older with lower-limb amputations. Arch Phys Med Rehabil. 2011;92(8):1257-63.

[PMID:21704978]

http://dx.doi.org/10.1016/j.apmr.2011.03.013

87. Hauer K, Lamb SE, Jorstad EC, Todd C, Becker C; PROFANE-Group. Systematic review of definitions and methods of measuring falls in randomised controlled fall prevention trials. Age Ageing. 2006;35(1):5-10.

[PMID:16364930] http://dx.doi.org/10.1093/ageing/afi218
88. Paulsen A, Overgaard S, Lauritsen JM. Quality of data entry using single entry, double entry and automated forms processing - an example based on a study of patient-reported outcomes. PLoS ONE. 2012;7(4): e35087. [PMID:22493733] http://dx.doi.org/10.1371/journal.pone.0035087

89. Gallagher P, Desmond D, MacLachlan M. A guide to the Trinity Amputation and Prosthesis Experience Scales (TAPES). Dublin (Ireland): Dublin Psychoprosthetics Group; 2007.

90. Gallagher P, Desmond D, MacLachlan M. A guide to the Trinity Amputation and Prosthesis Experience ScalesRevised (TAPES-R). Dublin (Ireland): Dublin Psychoprosthetics Group; 2011.

91. Garson GD. Hierarchical linear modeling: Guide and applications. Thousand Oaks (CA): Sage Publications; 2013.

92. Coelho A, Espanha M, Bruno P. Reliability of the six minute walk test and Timed Up \& Go test in persons with transfemoral amputation. Physiother. 2011;97(S1):S227.

93. Salarian A, Horak FB, Zampieri C, Carlson-Kuhta P, Nutt JG, Aminian K. iTUG, a sensitive and reliable measure of mobility. IEEE Trans Neural Syst Rehabil Eng. 2010; 18(3):303-10. [PMID:20388604] http://dx.doi.org/10.1109/TNSRE.2010.2047606

94. Wolf EJ, Everding VQ, Linberg AL, Schnall BL, Czerniecki JM, Gambel JM. Assessment of transfemoral amputees using C-Leg and Power Knee for ascending and descending inclines and steps. J Rehabil Res Dev. 2012; 49(6):831-42. [PMID:23299255] http://dx.doi.org/10.1682/JRRD.2010.12.0234

95. Buell NC, Willingham LL, Allyn KJ, Hafner BJ, Smith DG, editors. Evaluation of gait style to ascend and descend stairs for lower limb amputees. Proceedings of the 11th World Congress of the International Society for Prosthetics and Orthotics; 2004 Aug 1-6; Hong Kong.

96. Highsmith MJ, Kahle JT, Miro RM, Mengelkoch LJ. Ramp descent performance with the C-Leg and interrater reliability of the Hill Assessment Index. Prosthet Orthot Int. 2013;37(5):362-68. [PMID:23327837] http://dx.doi.org/10.1177/0309364612470482

97. Linberg AA, Roach KE, Campbell SM, Stoneman PD, Gaunaurd IA, Raya MA, Gomez-Orozco C, Gailey RS. Comparison of 6-minute walk test performance between male Active Duty soldiers and servicemembers with and without traumatic lower-limb loss. J Rehabil Res Dev. 2013;50(7):931-40. [PMID:24301430] http://dx.doi.org/10.1682/JRRD.2012.05.0098

98. Butte NF, Ekelund U, Westerterp KR. Assessing physical activity using wearable monitors: Measures of physical activity. Med Sci Sports Exerc. 2012;44(1 Suppl 1):S5-12. 
[PMID:22157774]

http://dx.doi.org/10.1249/MSS.0b013e3182399c0e

99. Klute GK, Berge JS, Orendurff MS, Williams RM, Czerniecki JM. Prosthetic intervention effects on activity of lower-extremity amputees. Arch Phys Med Rehabil. 2006;87(5):717-22. [PMID:16635636] http://dx.doi.org/10.1016/j.apmr.2006.02.007

100. Au SK, Herr H, Weber J, Martinez-Villalpando EC. Powered ankle-foot prosthesis for the improvement of amputee ambulation. Conf Proc IEEE Eng Med Biol Soc. 2007; 2007:3020-26. [PMID:18002631] http://dx.doi.org/10.1109/IEMBS.2007.4352965

101. Hafner BJ, Amtmann D, Abrahamson DC, Morgan SJ, Kajlich AJ, Salem R, editors. Normative PEQ-MS and ABC Scores among persons with lower limb loss. Proceedings of the American Academy of Orthotists \& Prosthetists (AAOP) 39th Annual Meeting and Scientific Symposium; 2013 Feb 20-23; Orlando, FL. Washington (DC): AAOP; 2013.

102. Gauthier-Gagnon C, Grisé MC, Potvin D. Enabling factors related to prosthetic use by people with transtibial and transfemoral amputation. Arch Phys Med Rehabil. 1999; 80(6):706-13. [PMID:10378500] http://dx.doi.org/10.1016/S0003-9993(99)90177-6

103. Nevitt MC, Cummings SR, Hudes ES. Risk factors for injurious falls: A prospective study. J Gerontol. 1991; 46(5):M164-70. [PMID:1890282] http://dx.doi.org/10.1093/geronj/46.5.M164

104. Tinetti ME, Doucette J, Claus E, Marottoli R. Risk factors for serious injury during falls by older persons in the community. J Am Geriatr Soc. 1995;43(11):1214-21. [PMID:7594154] http://dx.doi.org/10.1111/j.1532-5415.1995.tb07396.x

105. Gailey RS, Clark CR. Physical therapy. In: Smith DG, Michael JW, Bowker JH, editors. Atlas of amputations and limb deficiencies: Surgical, prosthetic, and rehabilita- tion principles. 3rd ed. Rosemont (IL): American Academy of Orthopaedic Surgeons; 2004. p. 589-619.

106. Barnett SD, Heinemann AW, Libin A, Houts AC, Gassaway J, Sen-Gupta S, Resch A, Brossart DF. Small $N$ designs for rehabilitation research. J Rehabil Res Dev. 2012;49(1):175-86. [PMID:22492346] http://dx.doi.org/10.1682/JRRD.2010.12.0242

107. Lechler K. The effect of a design change of a microprocessor-controlled knee on quality of life and performance based measures of mobility. Proceedings of the OTWorld 2014 International Congress; 2014 May 3-6; Leipzig, Germany. Dortmund (Germany): OTWorld; 2014.

108. Daniels T, Lechler K. Prosthetic knee design changes effecting two performance measures in transfemoral amputees. Proceedings of the American Academy of Orthotists and Prosthetists (AAOP) 40th National Meeting and Scientific Symposium; 2014 Feb 26-Mar 1; Chicago, IL. Washington (DC): AAOP; 2014.

Submitted for publication September 5, 2014. Accepted in revised form May 8, 2015.

This article and any supplementary material should be cited as follows:

Hafner BJ, Askew RL. Physical performance and selfreport outcomes associated with use of passive, adaptive, and active prosthetic knees in persons with unilateral, transfemoral amputation: Randomized crossover trial. J Rehabil Res Dev. 2015;52(6):677-700. http://dx.doi.org/10.1682/JRRD.2014.09.0210

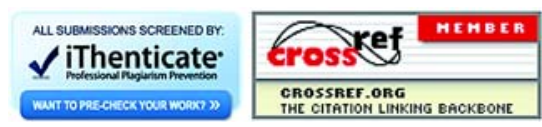


